NBER WORKING PAPER SERIES

PREDICTABILITY AND 'GOOD DEALS' IN CURRENCY MARKETS

Richard M. Levich

Valerio Poti

Working Paper 14597

http://www.nber.org/papers/w14597

\author{
NATIONAL BUREAU OF ECONOMIC RESEARCH \\ 1050 Massachusetts Avenue \\ Cambridge, MA 02138 \\ December 2008
}

The authors wish to thank Chris Neely (Federal Reserve Bank of St. Louis), Ming-Yuan Leon Li (National Cheng Kung University, Taiwan), Stephen Taylor (Lancaster University), Devraj Basu (EDHEC), and discussants and participants to the INFINITI 2007 conference, the EFM 2008 Symposium on Risk and Asset Management, the EFA 2008 meeting and seminars at Lancaster University and Reading University ICMA Centre for helpful comments and suggestions. Any remaining errors are the authors' sole responsibility. The views expressed herein are those of the author(s) and do not necessarily reflect the views of the National Bureau of Economic Research.

NBER working papers are circulated for discussion and comment purposes. They have not been peerreviewed or been subject to the review by the NBER Board of Directors that accompanies official NBER publications.

(C) 2008 by Richard M. Levich and Valerio Poti. All rights reserved. Short sections of text, not to exceed two paragraphs, may be quoted without explicit permission provided that full credit, including $\odot$ notice, is given to the source. 
Predictability and 'Good Deals' in Currency Markets

Richard M. Levich and Valerio Poti

NBER Working Paper No. 14597

December 2008

JEL No. F31,G15

\begin{abstract}
$\underline{\text { ABSTRACT }}$
This paper studies predictability of currency returns over the period 1971-2006. To assess the economic significance of currency predictability, we construct an upper bound on the explanatory power of predictive regressions. The upper bound is motivated by "no good-deal" restrictions that rule out unduly attractive investment opportunities. We find evidence that predictability often exceeds this bound. Excess-predictability is highest in the 1970s and tends to decrease over time, but it is still present in the final part of the sample period. Moreover, periods of high and low predictability tend to alternate. These stylized facts pose a challenge to Fama's (1970) Efficient Market Hypothesis but are consistent with Lo's (2004) Adaptive Market Hypothesis, coupled with slow convergence towards efficient markets. Strategies that attempt to exploit daily excess-predictability are very sensitive to transaction costs but those that exploit monthly predictability remain attractive even after realistic levels of transaction costs are taken into account and are not spanned by either the Fama and French (1993) equity-based factors or the AFX Currency Management Index.
\end{abstract}

Richard M. Levich

Stern School of Business

New York University

44 West 4th Street

New York, NY 10012

and NBER

RLEVICH@STERN.NYU.EDU

Valerio Poti

Dublin City University

Business School

Glasnevin

Dublin 9, Ireland

valerio.poti@dcu.ie 


\title{
Predictability and 'Good Deals' in Currency Markets
}

\begin{abstract}
This paper studies predictability of currency returns over the period 1971-2006. To assess the economic significance of returns predictability, we construct an upper bound on the explanatory power of predictive regressions. The upper bound is motivated by "no good-deal" restrictions that rule out unduly attractive investment opportunities. We find evidence that predictability often exceeds this bound. Excesspredictability is highest in the 1970s and tends to decrease over time, but it is still present in the final part of the sample period. Moreover, periods of high and low predictability tend to alternate. These stylized facts pose a challenge to Fama's (1970) Efficient Market Hypothesis but are consistent with Lo's (2004) Adaptive Market Hypothesis, coupled with slow convergence towards efficient markets. Strategies that attempt to exploit daily excess-predictability are very sensitive to transaction costs but those that exploit monthly predictability remain attractive even after realistic levels of transaction costs are taken into account and are not spanned either by the Fama and French (1993) equity-based factors or by the AFX Currency Management Index.
\end{abstract}

\section{Introduction}

In a literature that spans more than thirty years, various studies have reported that filter rules, moving average crossover rules, and other technical trading rules often result in statistically significant trading profits in currency markets. Beginning with Dooley and Shafer $(1976,1984)$ and continuing with Sweeney (1986), Levich and Thomas (1993), Neely, Weller and Dittmar (1997), Chang and Osler (1999), Gencay (1999), LeBaron (1999), Olson (2004), and Schulmeister (2006), among others, this evidence casts doubts on the simple efficient market hypothesis, even though it is not incompatible with efficient markets under time-varying risk premia and predictability induced by time-varying expected returns. More recently, however, and contrary to the bulk of these earlier findings, Pukthuanthong, Levich and Thomas (2007) find 
evidence of diminishing profitability of currency trading rules over time. In a comprehensive re-evaluation of the evidence hitherto provided by the extant literature, Neely, Weller and Ulrich (2007), also find evidence of declining profitability of technical trading rules.

In this paper, we directly assess whether currency returns are predictable to an extent that implies violation of the efficient market hypothesis (henceforth, EMH) and whether the evidence against the EMH has changed over time. To this end, we test whether, conditional on sensible restrictions on the volatility of the kernel that prices the assets, currency return predictability can be exploited to generate "good deals." The latter, following the terminology introduced by Cochrane and Saà Requeio (2000), Cerný and Hodges (2001) and Cochrane (2001), are investment opportunities that offer unduly high Sharpe ratios. To check on the availability of "good deals," we construct a theoretical time-varying upper bound on the explanatory power of predictive regressions. This bound, following Ross (2005), is ultimately a function of the volatility of the kernel that prices the assets traded in the economy, and it makes precise the intuitive connection between predictability, risk and reward for risk. In an efficient market, predictability should never exceed the bound as violations of the latter would imply the availability of "good deals," i.e. the possibility of exploiting predictability to generate unduly high Sharpe ratios. We thus test for violations of the EMH by comparing the explanatory power of predictive regressions with the theoretical "no good deal” bound. In doing so, we examine how predictability has varied over time and we compare and contrast predictability patterns with historical 
patterns in the profitability of technical trading rules considered by the extant literature.

In a stock market setting, related empirical literature includes the work of Campbell and Thompson (2005) and, with an emphasis on the role of conditioning information, Stremme, Basu, and Abhyankar (2005). Pesaran and Timmermann (1995) study the empirical link between predictability and risk (and thus reward for risk) by examining stock predictability at times of high and low market volatility. While these authors empirically exploit the link between the economy's maximal Sharpe ratio and the amount of admissible predictability, they do not directly test for violations of the $\mathrm{EMH}$. This is the approach we take here and it represents the main contribution of the paper. As pointed out by Taylor (2005), currency strategies tend to be, by far, more profitable than strategies that attempt to exploit the predictability of other asset classes. It is therefore rather surprising that this approach has not been previously attempted in a study of the efficiency of the currency market.

Empirically, we find evidence of recurring violations of the EMH. While such violations are especially severe in the initial part of the sample period, excesspredictability has not disappeared from the mid-1990s onwards, in contrast with the vanishing profitability of many popular technical trading rules reported in some recent studies, e.g. Neely, Weller and Ulrich (2007) and Pukthuanthong, Levich and Thomas (2007). Importantly, we find that predictability varies over time in a roughly cyclical manner with recurring albeit relatively short-lived episodes during which it 
exceeds the no good-deal upper bound. Suggestively, while this evidence is in contrast with the EMH, it is consistent with implications of Lo's (2004) Adaptive Market Hypothesis (AMH), in that bursts of predictability would appear to occur when shifts in market conditions require market participants to re-learn how to make efficient forecasts. While realistic levels of transaction costs, especially those arising as a result of 'price pressure,' e.g. Evans and Lyons (2002), can account for part of these violations and daily predictability is difficult to exploit because it would require frequent trading, strategies that exploit monthly predictability are much less sensitive to transaction costs and expand the investment opportunity set, thus rationalizing market participants' enduring tendency to engage in technical analysis and other active currency management practices.

In the next section, we outline the theoretical relation between predictability and time-varying expected returns, on the one hand, and trading rule profitability, on the other hand. We also introduce Ross' (2005) upper bound on the pricing kernel volatility and we discuss its implications for the maximum amount of predictability compatible with foreign exchange market efficiency. In Section 3, we describe our dataset. In Section 4, we describe the simple rolling autoregressions (AR) and autoregressive moving average models (ARMA) that we employ to capture predictability and present preliminary empirical results on the predictability of the currencies in our sample. In Section 5, we illustrate the link between predictability and the maximal Sharpe ratio of strategies that optimally attempt to exploit it. In Section 6, we consider the strategies that exploit estimated predictability to generate 
maximal Sharpe Ratios and we evaluate the impact of transaction costs on their profitability. In Section 7, in the spirit of White's (2000) reality checks, we assess the possible impact of sampling error on our inferences. In Section 8, we adopt an explicit multi-factor asset pricing perspective to assess to what extent strategies that exploit predictability expand the investment opportunity set of an investor endowed with rational expectations. In the final Section, we summarize our main findings and offer conclusions.

\section{Predictability, Time-Varying Expected Returns and Pricing Kernel Volatility}

Trading rule profitability implies that returns are to some extent predictable. This predictability, in turn, can stem either from time-varying expected returns, thus representing an equilibrium reward for risk, or from information contained in past prices unexploited by market participants. The former possibility is consistent with the notion of market efficiency, whereas the latter is not. Clearly, being able to fully discriminate between these two possibilities requires an equilibrium asset pricing model. More formally, consider the following model of excess returns:

$$
r_{t+1}=\mu_{t+1}+\varepsilon_{t+1}
$$

where

$$
\mu_{t+1} \equiv E\left(r_{t+1} \mid I_{t}\right) \equiv \mu\left(I_{t}\right)
$$


Here, $I_{t}$ is the information set at time $t$ and $\varepsilon_{t+1}$ is a conditionally zero-mean innovation. Then, following Ross (2005), we can write:

$$
\sigma^{2}\left(r_{t+1}\right)=\sigma_{\mu}^{2}+\sigma^{2}\left(\varepsilon_{t+1}\right)
$$

Here, $\sigma_{\mu}^{2}=\sigma^{2}\left[\mu\left(I_{t}\right)\right]$. Dividing both sides by $\sigma^{2}\left(r_{t+1}\right)$ and rearranging, we see that predictability is related to variation $\sigma_{\mu}^{2}$ in mean excess returns:

$$
R^{2}=1-\frac{\sigma^{2}\left(\varepsilon_{t+1}\right)}{\sigma^{2}\left(r_{t+1}\right)}=\frac{\sigma_{\mu}^{2}}{\sigma^{2}\left(r_{t+1}\right)}
$$

Variation in mean excess returns, in turn, can either come from variation in equilibrium risk premia, consistent with the $\mathrm{EMH}$, or from variation in abnormal mean returns that has not been exploited by the posited rational investor and thus is at odds with the EMH. To discriminate between these two possibilities, one must identify the rational component of $\sigma_{\mu}^{2}$. One way of doing this is to specify the model that determines $\mu_{t+1}$, but this approach entails the difficult task of specifying a full model of rational asset pricing, an ongoing endeavour that has not hitherto enjoyed unchallenged empirical success. An alternative approach, and the one that we pursue here, is to model $\sigma_{\mu}^{2}$ directly. To do this, we start from recognizing that, as noted by Ross (2005), we can write: 


$$
\sigma_{\mu}^{2} \leq E\left(\mu_{t+1}^{2}\right) \leq\left(1+R_{f}\right)^{2} \sigma^{2}\left(r_{t+1}\right) \sigma^{2}\left(m_{t+1}\right)
$$

Here, $R_{f}$ denotes the unconditional risk-free rate. The first inequality in (5), $\sigma_{\mu}^{2}=E\left[\mu_{t+1}-E\left(\mu_{t+1}\right)\right]^{2} \leq E\left(\mu_{t+1}^{2}\right)$, is based on an elementary result from descriptive statistics. The second inequality follows from the fact that, under noarbitrage and in a friction-less economy, the pricing kernel satisfies $\mu_{t+1}=\left(1+R_{f}\right) \operatorname{Cov}\left(r_{t+1}, m_{t+1} \mid I_{t}\right)$, while the correlation between the kernel and the asset excess return is bounded from above, in absolute value, by one. Using (5) in (4), we see that predictability is bounded from above by a quantity that depends on the amount of volatility of the kernel that prices the assets:

$$
R^{2} \leq\left(1+R_{f}\right)^{2} \sigma^{2}\left(m_{t+1}\right)
$$

Notably, the restriction in (6) holds unconditionally and thus for the in-sample coefficient of determination of any predictive regression. Under the rational expectations (RE) assumption originally formulated by Muth (1961), there is a tight link between the pricing kernel $m_{t+1}$ and investors' marginal utility. The RE assumption, in turn, is a necessary condition for the EMH to hold. These considerations suggest one way to mitigate the stark alternative between having to conduct a joint test of market efficiency and of a particular asset pricing model and not being able to discriminate between time-variation in equilibrium returns and abnormal profitability. A possible solution is to impose just enough restrictions on 
preferences to be able to restrict the volatility of the pricing kernel. This then yields restrictions on the maximal SR of the economy and on predictability.

To draw testable implications of the EMH for return predictability, we may thus proceed by assuming that there exist a group of greedy, risk-averse investors endowed with RE and that such investors are sufficiently homogeneous and wealthy to act as the marginal investor. Ross (2005) argues that the volatility of the intertemporal marginal rate of substitution of the marginal investor provides an upper bound to the volatility of the pricing kernel. If we restrict the curvature of this investor's utility function by imposing a relative risk aversion upper bound $R R A_{V}$, we can then place the following upper bound on the volatility of the kernel $m_{t+1}$ that prices the assets:

$$
\sigma^{2}\left(m_{t+1}\right) \leq \sigma^{2}\left(m_{V, t+1}\right) \cong R R A_{V}^{2} \sigma^{2}\left(r_{m, t+1}\right)
$$

Here, $m_{V, t+1}$ is the inter-temporal marginal rate of substitution between present and future wealth of an investor with relative risk aversion $R R A_{V}$, the latter is the relative risk aversion upper bound, and $\sigma\left(r_{m, t+1}\right)$ is the volatility of the market excess-return $r_{m, t+1}$. Based on (6), the pricing kernel volatility bound in (7) implies the following upper bound on the explanatory power of any predictive regression of asset returns:

$$
\phi \equiv\left(1+R_{f}\right)^{2} R R A_{V}^{2} \sigma^{2}\left(r_{m, t+1}\right) \cong R R A_{V}^{2} \sigma^{2}\left(r_{m, t+1}\right)
$$


Thus, under the EMH, we should observe $R^{2} \leq \phi$ and hence $R^{2} \leq R R A_{V}^{2} \sigma^{2}\left(r_{m, t+1}\right)$. To fix ideas, we may define a 'boundary violation index,' henceforth $B V I$, as the difference between the coefficient of determination of the estimated predictive regression and the predictability bound, i.e. $B V I=R^{2}-\phi$. The inequality in (6) implies that $B V I$ should be non-positive for all predictive regressions of the returns on all traded assets priced by the kernel $m$.

To operationalize (8), we need to specify the RRA upper bound $R R A_{V}$. Ross (2005) suggests imposing an upper bound of 5 on the relative risk aversion of the marginal investor, i.e. $R R A_{V} \leq 5$. Among the motivations advanced by Ross (2005) to do so, the one that most easily applies to a world with possibly non-normally distributed returns and non-quadratic utility is the simple observation that a relative risk aversion higher than 5 implies that the marginal investor would be willing to pay more than 10 percent per annum to avoid a 20 percent volatility of his wealth (i.e., about the unconditional volatility of the S\&P from 1926) which, by introspection, seems large.

It might be questioned whether a risk aversion upper bound of 5 is large enough in light of evidence, provided by the empirical literature on the "equity premium puzzle,” that points to much larger values. For example, Mehra and Prescott’s (1985) seminal study suggests that, given the real rate of return on risk free assets, risk aversion in excess of 50 is needed to explain the US equity premium in a model with frictionless capital markets and standard preference assumptions. As formally shown 
by Ross (2005), however, requiring the upper bound on RRA to exceed such empirical lower bounds provided by the literature on the "equity premium puzzle" would neglect the important circumstance that it is the marginal investors' risk aversion that matters, not the average investor's one, and in the former the risk aversion of wealthier and less risk averse investors takes a much larger weight than in the latter. Related arguments offered by Ross (2005) draw on the reasonable idea that aggregate consumption is much less volatile than the portfolio realistically held by the marginal investors, i.e. by investors who have the capacity of influencing prices.

A study by Meyer and Meyer (2005) has recently provided a comprehensive reevaluation of the hitherto rather scattered empirical evidence on investors' risk aversion. They show that relative risk aversion estimates reported by the extant literature are less heterogeneous and extreme if one takes into account measurement issues and the outcome variable with respect to which each study defines risk aversion. Using returns on stock investments as the outcome variable, calculations by Meyer and Meyer (2005) show that the RRA coefficient in the classical Friend and Blume’s (1975) study of household asset allocation choices ranges between 6.4 and 2.0, and decreases in investors' wealth. Using returns on the investors' overall wealth, including real estate and a measure of human capital, the RRA estimate ranges between 3.0 and 2.4. The same calculations show that the RRA implied by Barsky et al. (1997) experiment ranges between 0.8 and 1.6. ${ }^{1}$ Importantly, these

\footnotetext{
${ }^{1}$ When Meyer and Meyer (2005) consider estimates provided by studies based on asset pricing data, e.g. studies of the equity premium puzzle, they calculate somewhat higher values. Since in these studies the estimates of risk aversion are backed out parametrically from estimates of a particular asset
} 
estimates, at least for the wealthiest cohorts of investors, are always considerably lower than 5, i.e. the upper bound suggested by Ross (2005).

In light of the evidence reviewed by Meyer and Meyer (2005), alongside the RRA upper bound of 5 suggested by Ross (2005), we will also experiment with a lower value for the RRA upper bound, i.e. $R R A_{V}=2.5$. This value is just above the relative risk aversion of the marginal investor in the stock market, if we assume that this investor's preferences are described by a power utility function and we estimate the mean and volatility of the stock market using the historical average and standard deviation of the returns on the S\&P index since 1926. This bound implies that the marginal investor would be willing to pay up to 5 percent per annum, arguably still a relatively large amount, to avoid a 20 percent volatility of his wealth.

\section{Data}

Our data comprise daily and monthly returns on the spot exchange rate against the US Dollar of the major currencies (except those that were replaced by the Euro) for the period 1971-2006 taken by Bloomberg at the close of business in London at 6:00 p.m. GMT. ${ }^{2}$ These currencies are the Australian and Canadian Dollar (AUD and CAD, respectively), the Japanese Yen (JPY), the British Pound (GPB), the Swiss

pricing model, often based on a narrow definition of the market portfolio, they are of no interest for the purpose of computing the SDF volatility bound. Their use would imply a circular argument.

${ }^{2}$ We also use daily data, provided by Bloomberg, on the front month futures contract on the exchange rate of each of the above currencies against the US Dollar traded on the Chicago Mercantile Exchange (CME), but the results are not reported because they are qualitatively indistinguishable from, and quantitatively very similar to, the results for the underlying currencies. 
Franc (CHF) and the Euro (denoted as ECU/EUR because we combine data on the ECU before the introduction of the Euro in 1999 and on the latter after its launch). To proxy for the return on the market portfolio we use daily and monthly returns on the S\&P500 index constructed from last traded price and dividend data provided by Datastream.

\section{Currency Returns Predictability}

To conduct our tests of currency market efficiency, we estimate simple predictive regressions of the returns on the currencies in our sample. Next, we construct empirical counterparts to the predictability bound in (8) and we compare the coefficient of determination of the estimated predictive regressions with the constructed bound. As shown by Taylor (1994), among others, ARIMA models of exchange rates, and thus ARMA models of currency returns, capture substantial predictability. Our estimated models are thus specifications of the general ARMA(p,q) model, where $p$ denotes the autoregressive lag order and $q$ denotes the order of the moving average term:

$$
y_{t}=\text { const. }+b_{1} y_{t-1}+\ldots . .+b_{p} y_{t-p}+c_{1} u_{t-1}+\ldots . .+c_{q} u_{t-q}+u_{t}
$$

We apply versions of (9) to both currency returns and to returns adjusted by the interest differential (i.e. the differential between the funding cost in US Dollars and 
the return from reinvesting the funds in each one of the foreign currencies). ${ }^{3}$ We find that adjusting returns for the interest differential has virtually no impact on estimated predictability. This is because the volatility of the interest differential is negligible relative to currency returns volatility. Thus, to avoid duplication of indistinguishable predictability estimates, in the remainder of this study we work with currency return data only.

We start by estimating specifications of (9) over rolling windows of daily and monthly data for all currency returns in our sample, and recording their coefficients of determination. The predictive models are $\operatorname{ARMA}(5,0)$ or, equivalently, $\operatorname{AR}(5)$, for daily returns, and $\operatorname{ARMA}(5,2)$ for monthly returns. These specifications are chosen because they capture reasonably well the predictability of currencies in our sample, as suggested by Ljung-Box (1978) tests of the null of residual serial correlation, rejected for lags of up to the $36^{\text {th }}$ order. $^{4}$ The estimation window $l$ is one year, i.e. $l=$ 252 trading days, for daily data and 5 years, i.e. $l=5 \times 12=60$ months, for monthly data. In other word, each predictive autoregression is estimated over a window that runs between $t-l$ and $t$, where window length $l$ equals 252 for daily data and 60 for monthly data. For each currency $i$, this yields daily and monthly series of coefficients

\footnotetext{
${ }^{3}$ As a proxy for the risk-free rate on assets denominated in the currencies included in our dataset, we use daily middle rate data on Australian Dollar and German Mark inter-bank 'call money' deposits, on Canadian Dollar and Swiss Franc Euro-market short-term deposits (provided by the Financial Times/ICAP), on inter-bank overnight deposits in GBP and the middle rate implied by Japan's Gensaki T-Bill overnight contracts (a sort of repo contract used by arbitrageurs in Japan to finance forward positions). The rate on German Mark deposits is used as a proxy for the rate at which it is possible to invest funds denominated in ECU, while the overnight Euribor is used as a proxy for the rate at which it is possible to invest Euro denominated funds. As a proxy for the US risk-free rate, we use daily data on 1 month T-Bills (yields implied by the mid-price at the close of the secondary market). The interest rate data are taken from Datastream.

${ }^{4}$ The results of these tests are not tabulated to save space, but they are available from the authors upon request.
} 
of determination $R_{i,(t-l) \rightarrow t}^{2}$ estimated over rolling estimation window of returns from $t-l$ to $t$. To estimate a time-varying predictability bound $\phi_{t}$ at the daily (monthly) frequency, we proxy for the variance of the market return between $t-l$ and $t$, i.e. $\sigma_{(t-l) \rightarrow t}^{2}\left(r_{S \& P, t-l+s}\right)$ with $s \in[1,2 \ldots . . l]$, as the average, over rolling windows of 1 year (5 years) of daily (monthly) GARCH(1,1) S\&P500 returns $r_{S \& P, t-l+s}$. To compute $\phi_{t}$, as prescribed by (7), we then multiply $\sigma_{(t-l) \rightarrow t}^{2}\left(r_{S \& P, t-l+s}\right)$ by the square of the chosen RRA upper bound, i.e. by the square of the chosen value of $R R A_{V}$.

The resulting daily time-series of the rolling coefficients of determination for each currency are plotted in Figure 1, against the time series of the rolling predictability bound $\phi_{t}$ computed by setting $R R A_{V}=5$. The corresponding monthly series are qualitatively similar and they are not shown to save space. ${ }^{5}$ Visual inspection of Figure 1 reveals that the coefficients of determination of the estimated autoregressions are almost always above the bound. In fact, perhaps surprisingly, sub-periods when the bound is not violated represent the exception rather than the norm. As a consequence, as detailed in Table 1, the BVI is positive in more than 90 percent of the yearly rolling estimation windows for all currencies over the period 1971-2006 and three sub-periods of roughly equal length 1971-1983, 1984-1995, 1996-2006. Perhaps more remarkably, for most currencies and sub-periods, the frequency of positive BVI values, and thus predictability upper bound violations, is almost 100 percent.

\footnotetext{
${ }^{5}$ They are however available from the authors upon request.
} 


\section{Economic Significance of Predictability}

There is a tight link between predictability and the Sharpe ratio (SR) of strategies designed to exploit it. This link can be used to express predictability in units that have an immediate economic interpretation. To begin, it is worth recalling that, by a familiar Hansen and Jagannathan (1991) result, the economy maximal Sharpe ratio, and thus the maximum amount of profitability per unit of risk from any trading strategy is bounded from above by the volatility of the pricing kernel:

$$
\frac{E\left(\mu_{t+1}\right)}{\sigma\left(r_{t+1}\right)}=S R \leq\left(1+R_{f}\right) \sigma\left(m_{t+1}\right)
$$

Thus, from (6) and (10), it is clear that the volatility of the pricing kernel places an upper bound on both predictability and the maximal SR of the economy. This circumstance can be seen as a consequence of the fact that the coefficient of determination of predictive regressions can itself be interpreted as a maximal Sharpe ratio. To show this, we use an elementary statistical result that relates the variance of a random variable to its second moment and the square of its mean, and re-write the coefficient of determination in (4) as follows:

$$
R^{2}=\frac{\sigma_{\mu}^{2}}{\sigma_{r}^{2}}=\frac{1}{\sigma_{r}^{2}}\left(\frac{\mu^{\prime} \mu}{T}-\bar{\mu}^{2}\right)=\frac{1}{T} \mu^{\prime}\left(\frac{D D^{\prime}}{T}\right)^{-1} \mu-\frac{\bar{\mu}^{2}}{\sigma_{r}^{2}}=\mu^{\prime}\left(D D^{\prime}\right)^{-1} \mu-\frac{\bar{\mu}^{2}}{\sigma_{r}^{2}}
$$


Here, $\mu$ is the $T \times 1$ vector that stacks the conditional means of the currency return at each point in time $t, t=1, \ldots . T, \bar{\mu}$ is the unconditional mean return (a scalar) and $D$ denotes a $T \times T$ diagonal matrix with elements along the main diagonal that contain the conditional standard deviation of the currency return at each point in time $t$. In using this notation, we are essentially interpreting a strategy aimed at exploiting predictability as a portfolio made up of as many positions as data points in the sample period, each with its own 'conditional' SR. In monthly and higher frequency data, the second term on the far right-hand side of (11) is negligible, as it is the square of a typically small percentage number. ${ }^{6}$ In light of this, we can approximate the coefficient of determination as follows,

$$
R^{2} \cong \mu^{\prime}\left(D D^{\prime}\right)^{-1} \mu
$$

Interestingly, if one neglects the possible temporal interdependencies across conditional volatilities, i.e. if one neglects GARCH effects, (12) implies that the coefficient of determination in predictive regressions can be interpreted as the squared maximal SR attainable by forming 'portfolios,' i.e. strategies, of one-period positions in the currency under consideration. Up to a constant of proportionality, the weights with which each one-period position enters such strategy are then

$$
W=\left(D D^{\prime}\right)^{-1} \mu
$$

\footnotetext{
${ }^{6}$ Currencies have typically a drift rate very close to zero.
} 
Intuitively, a trading strategy based on the above inter-temporal weights amounts to using a predictive model that combines a directional signal, the conditional mean $\mu_{t}$, with a volatility filter, i.e. the elements $\sigma_{t}$ of $D$. These results are useful in that they offer insights into the economic significance of predictability and help appreciate its magnitude. Following this logic, we create an excess-predictability measure and, based on (12), we express it in annualized Sharpe ratios units. To do so, we rely on our boundary violation index introduced earlier $\left(B V I=R^{2}-\phi\right)$ and compute the square root of its annualized value,

$$
\gamma_{i, t_{0} \rightarrow t_{1}} \equiv \sqrt{B V I_{i, t_{0} \rightarrow t_{1}} \frac{l}{\text { years }}}
$$

Here, $t_{0}$ and $t_{1}$ are the beginning and end points, respectively, of the sub-periods over which we estimate $B V I_{i, t_{0} \rightarrow t_{1}}$ and compute $\gamma_{i, t_{0} \rightarrow t_{1}}$, i.e. 1971-1976, 1977-1982, 1983-1988, 1989-1994, 1995-2000 and 2001-2006. Clearly, $\gamma_{i, t_{0} \rightarrow t_{1}}$ is defined only when $B V I_{i, t_{0} \rightarrow t_{1}} \geq 0$. The quantity under the square root is multiplied by the ratio of the number of observations to the number of years in the estimation window length, i.e. $\frac{l}{\text { years }}$, to annualize (thus, $\frac{l}{\text { years }}=252$ when working with 1-year estimation windows of daily data and $\frac{l}{y e a r s}=\frac{60}{5}=12$ when using 5-year windows of monthly data). The quantity $\gamma_{i, t_{0} \rightarrow t_{1}}$ has an appealing economic interpretation. Based on (12), 
it can be seen as the annualized excess-SR that can be earned by exploiting predictability, assuming that one trades at the indicated frequency (i.e. daily or monthly). The value taken by $\gamma_{i, t_{0} \rightarrow t_{1}}$, therefore, can be seen as a measure of "good deal” availability. ${ }^{7}$

In Table 2, we report the computed values of $\gamma_{i, t_{0} \rightarrow t_{1}}$ based on estimates obtained using daily and monthly data. ${ }^{8}$ These excess predictability measures are in many cases positive and economically sizable. Excess-predictability is especially high in the initial part of the sample periods, i.e. in 1971-1976. In subsequent periods, the computed values of $\gamma_{i, t_{0} \rightarrow t_{1}}$ are generally lower, but a clear declining pattern can be detected only in the values taken by the $\gamma_{i, t_{0} \rightarrow t_{1}}$ of AUD, except for a surge in the final period, and to a lesser extent JPY. Except again for a surge in the final 5-year period, such a declining trend is more evident, especially in the daily case, in the arithmetic average of $\gamma_{i, t_{0} \rightarrow t_{1}}$ across all currencies reported in the last column. In the case of ECU/EUR, there is a burst of predictability between 1989 and 1994, possibly in relation to market adjustments leading to the adoption of the Euro.

Olson (2004) applies double moving-average rules to GBP, CHF, JPY and the German Mark exchange rate against the US dollar and finds evidence that they would

\footnotetext{
${ }^{7}$ We acknowledge that the empirical results are in-sample and may appear less convincing as evidence of "good deals" availability and thus EMH violations. However, our methodology is consistent with the essence of equation (6) and not a limitation. In addition, many currency speculators employed technical rules similar to (9) and captured returns in line with our calculations.

${ }^{8}$ Again, the values of this quantity computed using monthly data are qualitatively similar and they are not tabulated to save space. They are however available upon request.
} 
have generated abnormal profitability over the periods 1976-1980 and 1986-1990 but also that excess-profitability disappeared after 1991. Neely, Weller and Ulrich (2007) examine a more comprehensive set of trading rules and report similar findings. Large values of our measure of excess-predictability $\gamma_{i, t_{0} \rightarrow t_{1}}$, over the periods 1971-1976, 1977-1982 and, to a lesser extent, 1983-1988, are consistent with Olson's (2004) and Neely, Weller and Ulrich’s (2007) findings. As shown in Figure 2, the average BVI across our currencies declines over time and this is also broadly consistent with evidence of diminishing abnormal profitability of technical trading rules reported by these authors, in that decreasing excess-predictability presumably makes it more difficult for technical trading rules to spot profitable trends.

Our findings, however, do not support the view that excess-predictability has disappeared from the early 1990s onwards, or at least that it has been steadily declining since then. To the contrary, the increase of the excess-predictability of a number of currencies, in the latter part of the sample period, is in contrast with this conclusion. To reconcile our evidence with the findings of diminishing profitability of technical trading rules reported by Olson (2004) and Neely, Weller and Ulrich (2007), one must posit that the rules considered by these authors do not capture all predictability. Evidence provided by Pukthuanthong, Levich and Thomas (2007) suggests that trend-following rules that were once profitable now lose money, whereas the corresponding counter-trending rules, i.e. rules that do exactly the opposite, are increasingly profitable. Our excess-predictability measure would capture the excess-profitability of both types of strategies. Our results, contrary to 
Olson’s (2004) and Neely, Weller and Ulrich’s (2007) findings, are also consistent with evidence of high trading profits from momentum strategies during the 1990s reported by Okunev and White (2003), as we generally do not find evidence of declining excess-predictability after 1991.

On balance, our findings represent intriguing prima facie evidence that there is nonnegligible excess-predictability in currency markets and that this excesspredictability, in recent years, has declined from its 1970s peaks without disappearing entirely. This implies that there might be good reasons why currency traders, in their pursuit of profitability and against academic advice, have long engaged in technical analysis and other practices aimed at exploiting predictable patterns in currency returns. Taken at face value, these results represent potential evidence against the EMH. There is the possibility, however, that high transaction costs might have to be incurred to exploit the estimated predictability and that our estimates of the coefficient of determination $\mathrm{R}^{2}$ be inflated by sampling error. We now investigate these important possibilities in turn.

\section{The Impact of Transaction Costs}

To gain insights into the impact of transaction costs, it is necessary to consider the strategies that would have to be implemented in order to exploit the estimated predictability. To this end, we use the weights in (13) to construct maximal SR strategies for each currency and calculate their returns after transaction costs. Much 
of the extant literature considers transaction costs of about 0.05 percent, or 5 basis points, realistic for a typical round trip trade between professional counterparts, see Levich and Thomas (1993) and Neely, Weller and Dittmar (1997). This corresponds to about 2-3 basis points on each one way, i.e. buy or sell, transaction. In calculating the return to these strategies, therefore, we allow for transaction costs of up to 5 basis points. For comparison, we also experiment with transaction costs of 25 basis points. In the context of our ARMA(p,q), the mean vector in (13) equals the conditional mean of (9), i.e. $\mu_{t}=y_{t}-u_{t}$, while $D D^{\prime}$ collapses to the currency return sample variance times a $T \times T$ identity matrix, i.e. $\sigma^{2}\left(y_{t+1}\right) I_{T \times T}$.

In Figure 3, to illustrate, we plot the time-varying weights, calculated using (13) and normalized to add up to unity, of the maximal SR strategies that exploit the daily and monthly predictability of the Canadian Dollar, based on $\operatorname{AR}(5)$ and $\operatorname{ARMA}(5,2)$ specifications, respectively, estimated over the period 1995-2006. The corresponding plots for other currencies, predictive models and sample periods are not reported to save space. In all cases, there is substantial variation in the weights of the (daily) positions entailed by the maximal SR strategies that optimally exploit daily predictability, as a result of the conditional time-variation of the mean of the return process. There is much less variation in the weights of the (monthly) positions required to exploit monthly predictability. This means that strategies that exploit daily predictability are rebalanced more frequently than those that exploit monthly predictability and therefore transaction costs are likely to have a greater impact on the former than on the latter. Notably, in classic filter and moving-average strategies, 
trading positions change relatively infrequently. ${ }^{9}$ This is because such strategies often exploit predictability at low frequency and thus avoid the burden of high transaction costs.

In Table 3, we report the SRs offered by maximal SR strategies that exploit daily and monthly predictability. As before, the predictive model for daily returns is $\operatorname{ARMA}(5,0)$ whereas the predictive model for monthly returns is ARMA(5,2). For all the currencies under consideration, except CHF, transaction costs of 3 basis points are enough to lower the SRs of the daily strategies below the level that corresponds to the tightest predictability bound and the maximal SRs of the strategies based on the daily predictability of AUD, JPY and ECU/Euro become negative. With transaction costs of five basis points, the maximal SRs of daily strategies are negative for all currencies. The strategies that exploit monthly predictability, however, are much less sensitive to transaction costs. In all sub-sample periods, the SRs for the maximal SR monthly strategies are positive even with transaction costs of 5 basis points. More importantly, they often exceed the threshold implied by the predictability bound, reported in the last two columns, even under $R R A_{V}=5$. Crucially, this happens in the latter sample period too, contrary to studies cited earlier which find that certain popular trading strategies are not profitable from the 1990s onwards.

\footnotetext{
${ }^{9}$ For example, Levich and Thomas (1993) report that over their 15 year sample period of major currencies, the 5 day / 20 day moving average rule traded 13 times per year.
} 
Overall, these findings suggest that, while daily predictability cannot be exploited because of high transaction costs, lower frequency (monthly) predictability might be amenable to generate high SRs because trading frequency and transaction costs are reduced. The latter circumstance poses a challenge to the EMH, as in an efficient market investors endowed with rational expectations should detect excesspredictability and recognize and exploit the attendant "good deal” opportunities, thereby bringing predictability within the bound provided by the volatility of the pricing kernel. In turn, this suggests that trading strategies based on low-frequency currency predictability might be attractive for professional investors, at least for those who can use available information better than the representative investor and face moderate yet realistic levels of transaction costs.

A word of caution is in order at this point with respect to the likely magnitude of any available "good deal." There is substantial evidence that transaction costs depend on the size of the transaction and, more specifically, on "price pressure.” For example, Evans and Lyons (2002) estimate that a buy order of 1 million US dollars increases the execution exchange rate against the Deutsche Mark and the Japanese Yen by as much as 0.54 percent, or 54 basis points. Similar figures are provided by Berger, Chernenko, Howorka and Write (2006), at least for trades executed over a daily horizon. As shown in Table 3, transaction costs of 25 basis points are enough, with few exceptions, to lower SRs below the threshold that corresponds to the wider predictability bound, i.e. the bound corresponding to $R R A_{V}=5$, and often below the level implied by the tighter predictability bound, i.e. the bound corresponding to 
$R R A_{V}=2.5$. Similar or higher levels of transaction costs, as implied by the evidence provided by the literature on "price pressure," are to be expected for large transactions.

High transaction costs by themselves generate apparent excess-predictability. Roll (1984), for example, show that the bid-ask bounce induces an amount of predictability that depends on the relative magnitude of the bid-ask spread and exchange rate variability. This predictability is not exploitable by construction, because any attempt to exploit it would be costly. The evidence of high predictability and these considerations on the impact of transaction costs on the profitability of large-size transaction, taken together, allow one to rationalize, on the one hand, the frequent occurrence of studies that find abnormally profitable strategies and, on the other hand, the persistence of excess-profitability. We conjecture that available "good deal” opportunities might persist over time because, though in principle advantageous, they do not attract enough investors or investors with enough risk capital, perhaps due to the presence of a fixed component of transaction costs, e.g. entry costs. We leave, however, a formal investigation of this issue, i.e. the link between transaction costs, transaction size and persistence of profit opportunities, for future research. 


\section{The Impact of Sampling Error}

To gain insight into the impact of sampling error on our assessment of excesspredictability, we compare the estimated BVI with a measure of sampling error of the coefficient of determination of the estimated predictive regressions. To this end, we construct a modified version of the $B V I$, i.e. $B V I_{a d j}$, by reducing $B V I$ by an amount that reflects an estimate of sampling error at a specified confidence level,

$$
B V I_{a d j}=B V I-\text { S.e. } R^{2}, 95 \%
$$

Here, s.e. $_{R^{2}, 95 \%}$ denotes the sampling error, at the 95 percent confidence level, of the estimated coefficient of determination of the predictive regression. To obtain an estimate of sampling error, we use the asymptotic distribution of the coefficient of determination $\hat{R}^{2}$ of the $\operatorname{ARMA}(\mathrm{p}, \mathrm{q})$ model, valid when the model parameters are estimated, derived by Hosking (1979), i.e. ${ }^{10}$

$$
\hat{R}^{2} \sim N\left(R^{2}, \frac{4\left(1-R^{2}\right)^{2}}{T} \sum_{k=1}^{\infty} \rho_{k}^{2}\right)
$$

Here, $R^{2}$ is the coefficient of determination under the null hypothesis and $\rho_{k}=\frac{E\left(y_{t} y_{t-k}\right)}{E\left(y_{t}\right)}$ denotes the $k$-th order autocorrelation of the series $y_{t}$. In our case, $y_{t}$ 
is a currency return and $R^{2}$ is bounded from above by the predictability upper bound, i.e. $R^{2} \leq \phi$. The quantity $1.64 \times \sqrt{\frac{4\left(1-R^{2}\right)^{2}}{T} \sum_{k=1}^{\infty} \rho_{k}^{2}}$, then, provides an estimator of $s . e_{R^{2}, 95 \%}$. Letting $R^{2}=\phi$, the above result can be rewritten to obtain a convenient statistic for one-tailed tests that estimated predictability does not exceed the upper bound $\phi$, i.e.

$$
H=\sqrt{T}\left(\hat{R}^{2}-\phi\right) \sim N\left(0,4(1-\phi)^{2} \sum_{k=1}^{\infty} \rho_{k}^{2}\right)
$$

Because, as shown in Table 3 and discussed in the preceding section, the profitability of strategies that exploit daily predictability is seriously affected by transaction costs, we focus on the assessment of the statistical significance of monthly predictability. The times series of $B V I_{a d j}$, based on $\operatorname{ARMA}(5,2)$ predictive regressions estimated using rolling 5-year windows of monthly data, i.e. letting $l=60$ and years $=5$, are plotted in Figure $4 .{ }^{11}$ The ARMA(5,2) predictive regressions are estimated using the Broyden, Fletcher, Goldfarb and Shanno method described in Press et al. (1988). In constructing $B V I_{a d j}$, we use $\frac{1}{m} \sum_{k=1}^{m} \rho_{k}^{2}$ as a sample counterpart of $\frac{1}{T} \sum_{k=1}^{\infty} \rho_{k}^{2}$, where $m=\min [l / 4,2 \sqrt{l}]=15 .{ }^{12}$ We do this because the computation of the variance of the

\footnotetext{
${ }^{10}$ In the original article by Hosking (1979), the term $\left(1-R^{2}\right)$ was not squared, but this error was subsequently amended by the author in an erratum.

${ }^{11}$ The corresponding series constructed using daily data, i.e. using the coefficient of determination of ARMA(5,0) predictive regressions estimated over rolling 1-year windows of daily data, are qualitatively similar and are not plotted to save space.

${ }^{12}$ We the implementation of this algorithm provided by the econometric software RATS ${ }^{\mathrm{TM}}$.
} 
coefficient of determination, according to Hosking (1978), requires a consistent estimate of $\sum_{k=1}^{\infty} \rho_{k}^{2} \cdot{ }^{13}$ Figure 4 shows that bursts of statistically significant excesspredictability occurred at various points over the sample period, for example in the 1970s and 1980s, around the European Monetary System (EMS) crisis of the early 1990s and at the time of the Asian Financial Crisis in the second half of the 1990s. In the more recent part of the sample period, the return on a number of currencies, especially AUD, JPY, CHF and EUR also experienced episodes of significant excess-predictability. Overall, as emphasized by the 12-month moving average superimposed to the BVI series, statistically significant excess-predictability displays a roughly cyclical pattern, i.e. periods of high and low predictability alternate over time, consistent with Lo's (2004) AMH. Suggestively, episodes of excesspredictability appear to present themselves at times of changing economic conditions, only to relatively quickly come to an end as market participants re-learn efficient information processing, i.e. to do so in the context of the new economic conditions.

Next, we compute $B V I_{a d j}$ over estimation windows corresponding to six 5-year long non overlapping periods of roughly equal length between 1972 and 2006 . We then 'translate' the computed $B V I_{a d j}$ values into annualized SRs units, i.e. we construct a version of $\gamma_{i, t_{0} \rightarrow t_{1}}$ adjusted for sampling error,

${ }^{13}$ If we estimated the latter using $m=\infty$, we would have very few observations at our disposal to estimate autocorrelations of high orders, i.e. with $k$ large and close to $T$. This would lead to inconsistent estimates of $\rho_{k}$ and thus of the sampling error of $R^{2}$. 


$$
\gamma_{\text {adj } ; i, t_{0} \rightarrow t_{1}} \equiv \sqrt{B V I_{a d j ; i, t_{0} \rightarrow t_{1}} \frac{l}{\text { years }}}
$$

As before, $t_{0}$ and $t_{1}$ are the beginning and end points, respectively, of the subperiods over which we compute $\gamma_{a d j ; i, t_{0} \rightarrow t_{1}}$. We estimate $B V I_{a d j}$ and $\gamma_{a d j ; i, t_{0} \rightarrow t_{1}}$ using both daily and monthly data but we tabulate results for monthly data only, due to the high transaction costs that must be incurred to exploit daily predictability and thus due to its likely limited economic significance. For the case of monthly data, the ratio $\frac{l}{\text { years }}$, that serves to annualize, equals 12 . The quantity $\gamma_{a d j ; i, t_{0} \rightarrow t_{1}}$ can be seen as the annualized excess-SR that can be earned, at the 95 percent confidence level, by exploiting excess predictability, assuming that one trades at the indicated frequency (i.e., monthly). The predictive regressions, $\operatorname{ARMA}(5,2)$ for monthly data, are estimated using maximum likelihood ${ }^{14}$. The constructed values of $\gamma_{a d j ; i, t_{0} \rightarrow t_{1}}$ are reported in Table 4, alongside Hosking's (1978) $H$ statistic and associated p-value of the test that estimated predictability does not exceed the upper bound. They suggest, in the 1980s, the presence of excess-predictability of AUD, JPY and, to a lesser extent, CAD. The evidence of excess-predictability is still present in the 1990s for GBP and CHF, with SRs in excess of the RRA = 5 bound as large as 9.67 and almost 38.81 percent, respectively. GBP also exhibits high statistically significant excesspredictability in a number of periods.

\footnotetext{
${ }^{14}$ We use the implementation of this method available in the econometric package RATS ${ }^{\mathrm{TM}}$.
} 
The estimate of sampling error used to construct $B V I_{a d j}$ might be biased or not converge fast enough to provide a reliable estimate of sampling error of the coefficient of determination of the estimated predictive regressions. In fact, Hosking's (1979) result is only valid asymptotically in large samples and it assumes that the estimated predictive regression be the true data-generating model. ${ }^{15}$ This might lead to an over-estimate of sampling error. To double-check on our assessment of sampling error and especially as a further robustness check on our inferences about the presence of excess-predictability, we bootstrap 2-tailed confidence intervals for the coefficient of determination of the estimated predictive regressions. This allows us to take sampling error of the coefficient of determination into account without having to rely on large sample asymptotics and the normality assumptions made by Hosking (1979). To conduct our bootstrapping experiment, we estimate the parameters of the chosen predictive $\operatorname{ARMA}(p, q)$ model and store the residuals. We then re-sample 1,000 times, with replacement, blocks of 5 consecutive realizations from the stored residuals time-series, i.e. we employ 'block re-sampling' to capture any residual serial correlation not explained by the estimated predictive regression. Using the time-series of the re-sampled residuals and the point estimates of the predictive regression parameters, we generate 1,000 separate bootstrapped currency return series, for which we then re-estimate the chosen predictive $\operatorname{ARMA}(p, q)$ model and record the coefficient of determination $\mathrm{R}^{2}$. This generates a bootstrapped distribution of the latter. This approach to bootstrapping is known as estimation-

\footnotetext{
${ }^{15}$ On a related note, Kurz-Kim and Loretan (2007) show that, in the case of the well-known finite sample F-distribution of the $\mathrm{R}^{2}$ under the null that the latter is zero, this might be a concrete danger when the normality assumption fails and the regression variables have fat tails distributions, as it is often the case for regressions involving currency returns.
} 
based bootstrap. It has been introduced by Freedman and Peters (1984) and Peters and Freedman (1984), and has been used by Karolyi and Kho (2004) to test the profitability of momentum strategies.

In Table 5, we report monthly predictability upper bounds and bootstrapped confidence intervals for the coefficient of determination of predictive regressions estimated using monthly data. The predictive regressions are $\operatorname{ARMA}(5,2)$ and, for comparison, more parsimonious $\operatorname{ARMA}(5,0)$. The predictive regressions are estimated over the whole sample period and the three sub-periods 1971-1983, 19841995, and 1996-2006. ${ }^{16}$ When the predictive model is ARMA(5,0), evidence of excess-predictability is not particularly strong. When one considers the explanatory power of the ARMA(5,2) models, however, the bootstrapped confidence intervals are almost always in excess of the tightest bound, i.e. the bound corresponding to $R R A_{V}$ $=2.5$. The wider bound, i.e. the bound corresponding to $R R A_{V}=5.0$, is violated in the case of CAD and JPY in the initial 1971-1982 sub-sample period and in the case of JPY also in the final sub-sample period, i.e. in 1995-2006.

To interpret these results, it is useful to consider that, when the $95^{\text {th }}$ percentile of the bootstrapped coefficient of determination distribution exceeds the predictability bound for a given risk aversion bound $R R A_{V}$, an investor endowed with rational expectations and RRA no larger than $R R A_{V}$ could have exploited currency predictability to reliably (i.e., with 95 percent confidence) generate SRs in excess of the square root of the predictability bound. For example, by exploiting the monthly 
ARMA(5,2) predictability of AUD, JPY and CHF over the period 1971-2006 and under $R R A_{V}=2.5$, such an investor could have earned excess-SRs at least as large as the square root of 1.28 percent. This amounts to an excess-SR of 39.2 percent per annum. Similar calculations show that the same investor could have earned excessSRs of 40.1, 44.0 and 38.6 percent over the periods 1971-1983, 1984-1995, 19962006, respectively, by exploiting the predictability of either currency in our sample (except, of course, ECU/EUR over the initial sample period). The monthly predictability of CAD and JPY over the period 1971-1983 and of JPY in 1996-2006 exceeds the predictability bound even under $R R A_{V}=5.0$. Thus, optimally exploiting the monthly predictability of CAD and JPY over the period 1971-1983 and of JPY in 1996-2006 would have allowed for SRs in excess of 80.1 and 77.1 percent, respectively.

The bootstrapped distributions of the coefficient of determination of predictive regressions reported in Tables 5 provide stronger evidence of excess-predictability than the estimates adjusted for Hosking's (1979) sampling error reported in Table 4. Both, however, suggest that an investor endowed with rational expectations could have exploited predictability, over a number of portions of the 1971-2006 sample period, to reliably generate SRs in excess of the good-deal thresholds corresponding to $R R A_{V}=2.5$ or even $R R A_{V}=5$. Because the performance of strategies that exploit monthly predictabilities is robust to transaction costs, this can be seen as evidence of good-deal availability both before and after transaction costs. Such evidence becomes weaker but does not entirely disappear in the more recent part of the sample period.

\footnotetext{
${ }^{16}$ Tests for residual serial correlation are conducted using Ljung-Box (1978) Q-statistic.
} 
This contrasts with the emerging view (in Taylor (2005) and Neely, Weller and Ulrich (2007)) that the markets of the major currencies no longer allow for trading profits.

\section{Currency Predictability and the Investment Opportunity Set}

To more explicitly assess to what extent predictability-based strategies expand the investment opportunity set, we first combine the maximal SR strategies for the individual currencies into an overall maximal SR strategy. We then compare the performance of the latter to a benchmark currency management strategy, i.e. the AFX index introduced by Lequeux and Acar (1998) and designed to track the performance of technical analysis rules commonly followed by active currency managers. Monthly values of this index are available from 1984 onwards. To take a conservative stance on the amount of exploitable or detectable predictability, we consider the maximal SR strategies that exploit the predictability implied by parsimonious ARMA(5,0) models of monthly currency returns. We denote by $r$ the excess return on the overall maximal SR strategy. The weights with which the maximal SR strategies for the individual currencies enter the overall maximal SR strategy, normalized to sum to one and reported in the first column of Table 6, are calculated as follows:

$$
w^{*}=\Sigma^{*-1} \bar{\mu}^{*}
$$


Here, $\Sigma^{*}$ denotes the variance-covariance matrix of the returns on the individual currencies maximal SR strategies and $\bar{\mu}^{*}$ denotes the vector of their unconditional expected returns. As reported in the second column of Table 6, the SR of $r^{*}$ is considerably higher than the SR of the individual currencies maximal SRs strategies. Especially in the more recent sub-sample period, it is also much higher than the SR of the AFX currency management index. In fact, while the SR of the AFX currency management index is lower in 1996-2006 than in 1986-2006, the SR of $r^{*}$ is actually much higher in the more recent sub-sample period. As shown in Table 7, the correlation of the AFX index and $r^{*}$ drops from 52.36 percent in 1985-1990 to just over 41 percent in 2003-2006. During the same time, while the SR of the AFX index becomes negative, the SR of $r$ * exceeds 106 percent per annum.

Taken together, these results suggest that the combination of moving-average rules and currencies considered by the AFX index does not fully capture the estimated amount of currency predictability, especially in recent times. Figure 5 shows the rolling 12-month SR of the AFX index and $r^{*}$. These series move remarkably closely until about 1996 but subsequently their correlation breaks down. As shown in Table 7, their correlation becomes negative in 2003-2006. This suggests that, while the excess-profitability of the specific moving average rules considered by the AFX index might have dried up as market participants have employed them in their trading strategies, alternative and not yet fully exploited sources of excess-profitability have emerged and manifest themselves as excess-predictability. Again, this is consistent 
with the Adaptive Market Hypothesis (AMH) perspective put forth by Lo (2004) and advocated, in a currency market setting, by Neely, Weller and Ulrich (2007).

Finally, we take an explicit asset pricing perspective and we ask whether maximal SR predictability-based strategies are spanned by known equity market factors, which some studies suggest span the investment opportunity set. To this end, we simply regress the excess return on each one of the individual currencies maximal SR strategies, the overall SR strategy and, for comparison, the AFX currency management index against the Fama and French (1993) factors, i.e. we estimate

$$
r_{i, t}=\alpha_{i}+\beta_{i, m} r_{m, t}+\beta_{i, S M B} S M B_{t}+\beta_{i, H M L} H M L_{t}+\varepsilon_{i, t}
$$

Here, $r_{i, t}$ is the excess return on either the overall maximal SR strategy, $r_{t}{ }^{*}$, an individual currency maximal SR strategy or the AFX currency management index, $\alpha_{i}$ denotes the regression intercept, $r_{m, t}, S M B_{t}$ and $H M L_{t}$ are the excess-returns on the Fama and French (1993) market, size and book-to market factor mimicking portfolios, respectively, and $\beta_{i, m}, \beta_{i, S M B}$ and $\beta_{i, H M L}$ denote their corresponding factor loadings, while $\varepsilon_{i, t}$ denotes the regression error term. As shown in Table 6, the maximal SR strategies for a number of individual currencies and the overall maximal SR strategy offer a positive and statistically significant $\alpha_{i}$, especially over the period 1984-2006. Perhaps more interestingly, the factor loadings on these strategies are always either very small and statistically insignificant or negative and statistically significant. This implies that the strategies either carry little systematic risk or they 
act as a hedge against the latter. ${ }^{17}$ This fact, coupled with the sign and magnitude of the factor loadings and the significance of the 'alpha' terms, suggest that the strategies that exploit currency predictability expand the investment opportunity set, i.e. they are not spanned by the Fama and French (1993) factors.

To formally test whether this is the case, we use the 'alphas' of these strategies to compute a Gibson, Ross and Shanken (1989) test-statistic, i.e. we form

$$
G R S=\frac{T-N-K}{K}\left[1+E(f)^{\prime} \Omega^{-1} E(f)\right]^{-1} \alpha \Sigma^{-1} \alpha \sim F_{K, T-N-K}
$$

Here, $T$ is the sample size, $N$ is the number of factors $f, E()$ denotes the unconditional expectation operator, $\Omega$ denotes the factor variance-covariance matrix, $\alpha$ is the vector of the intercepts from (15), and $\Sigma$ is the variance-covariance matrix of the strategies residuals not explained by the factor model, i.e. the error terms $\varepsilon_{t}$ in (15).

In our application, there are 6 maximal SR strategies that exploit the predictability of AUD, CAD, JPY, GBP, CHF and ECU/EUR and thus $K=6$, while the factors $f$ are the excess-returns on the Fama and French (1993) market, size and book-to market factor mimicking portfolios and thus $N=3$. The GRS statistics for the periods 19862006 and 1996-2006, reported in the last column of Table 6, are both highly statistically significant. In computing (16), we estimate population moments using

${ }^{17}$ A recent study by Burnside, et al. (2006) also shows that currency returns are uncorrelated with 
their sample counterparts. Gibson, Ross and Shanken (1989) demonstrate that comparing the GRS statistic with the 5 percent critical value of its finite sample distribution (under the null that pricing errors equal zero), i.e. the F distribution with $K$ and $T-N-K$ degrees of freedom, amounts to testing whether the factors are on the ex-post mean-variance frontier. The significance of the GRS statistic in our tests thus implies that the Fama and French (1993) factors do not span the predictabilitybased strategies and, therefore, that the latter expand the efficient frontier, at least from the point of view of a rational mean-variance investor.

\section{Conclusions, Final Remarks and Future Work}

In this paper, we assess the statistical and, more importantly, economic significance of predictability in currency returns over the period 1971-2006. We find that, even under a relatively wide bound on relative risk aversion, predictability often violates the attendant theoretically motivated upper bound. Closer scrutiny reveals that the performance of strategies that attempt to optimally exploit daily predictability is very sensitive to the level of transaction costs and this limits the extent to which it can be exploited to generate genuine "good deals." On the other hand, the performance of strategies that attempt to optimally exploit monthly predictability is robust to moderate yet realistic level of transaction costs. Taken at face value, this evidence implies the availability of "good deals," at least at the monthly frequency, and thus violation of the EMH under a broad class of asset pricing models, for conservative values of the marginal investor's relative risk aversion and for realistic levels of

other asset classes. 
transaction costs. Excess-predictability is highest in the 1970 s and, for most currencies in our sample, tends to decrease over time without disappearing. In addition, we find that strategies based on monthly predictability expand the investment opportunity set, even after transaction costs. This effect is also present in the latter part of the sample period and, crucially, it does not disappear after the mid1990s, contrary to the conclusions of several recent studies. Taken together, our findings pose a challenge to the EMH but they are consistent with Lo's (2004) AMH. ${ }^{18}$

Offering confirmation that technical trading is still alive in the currency domain, Pojarliev and Levich (2008) have shown that currency hedge funds, behave as if they follow standard technical trading strategies. Over the 1990-2006 period, the authors show that a technical trading factor was the single most significant explanatory variable of currency hedge fund returns. The returns of currency hedge funds were significantly correlated with the AFX index over the 1990-2006 period. The relationship declined somewhat over a 2001-06 sub-sample, but remained highly significant. And in the present 2008 financial crisis, Deutsche Bank (2008) reports that this year their technical trading currency benchmark has earned $8.8 \%$ over LIBOR through October 20, similar to magnitudes observed in the 1970s and 1980s.

\footnotetext{
${ }^{18}$ On a similar note, Lo (2005) offers, on pp. 35-36, a suggestive discussion of the cyclical behaviour of the first-order autocorrelation of the S\&P Composite Index. In particular, on p. 35, Lo (2005) argues: "Rather than the inexorable trend to higher efficiency predicted by the EMH, the AMH implies considerably more complex market dynamics, with cycles as well as trends, and panics, manias, bubbles, crashes and other phenomena that are routinely witnessed in natural market ecologies. These dynamics provide the motivation for active management.”
} 
A possible avenue of future research is a more formal investigation of whether the estimated $\mathrm{R}^{2}$ series contains a time trend, a cyclical component and one or more structural breaks. Considering cross-rates and a wider sample of countries, possibly including emerging economies, might also allow the estimation of possible time trends and structural breaks, perhaps adopting a panel approach. A random coefficient model, along the lines of Swamy (1970), would appear particularly promising to accommodate the difficulty of modelling possible sources of crosssectional variation in the predictability of currency returns. These extensions would make it possible to better address the important question of whether predictability in excess of a level that can be judged consistent with the EMH has become milder over time as a result of learning by economic agents, or whether excess-predictability exhibits a persistently cyclical pattern that can be more easily explained by Lo's (2004) AMH. 
Figure 1

Daily AR(5) Predictability vs. Predictability Bound

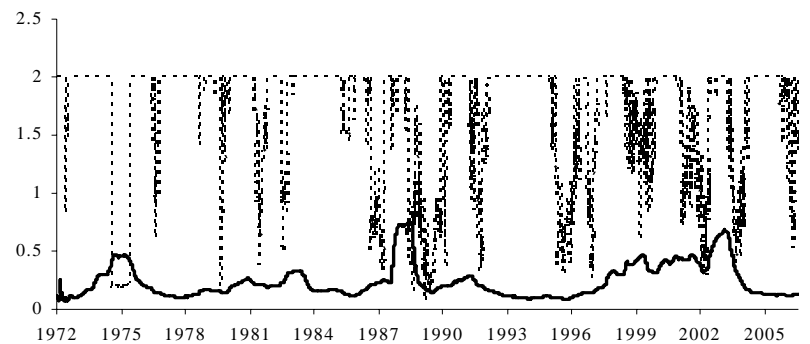

........AUD $\longrightarrow$ R Sq. Bound

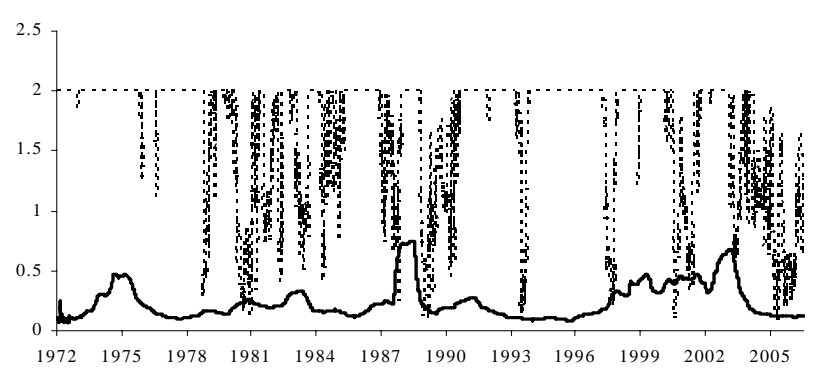

…...GBP $\longrightarrow$ R Sq. Bound

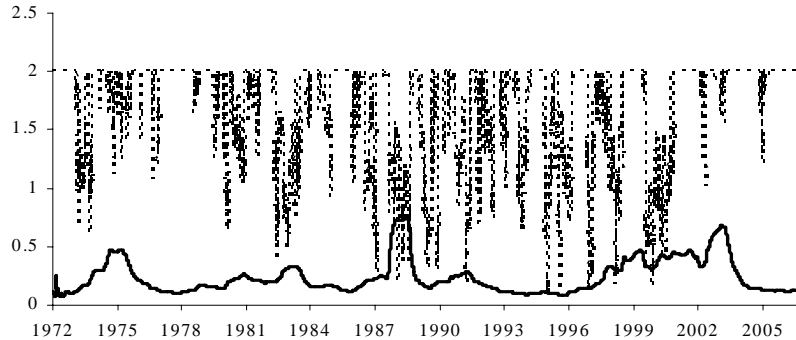

…. CAD $\longrightarrow$ R Sq. Bound

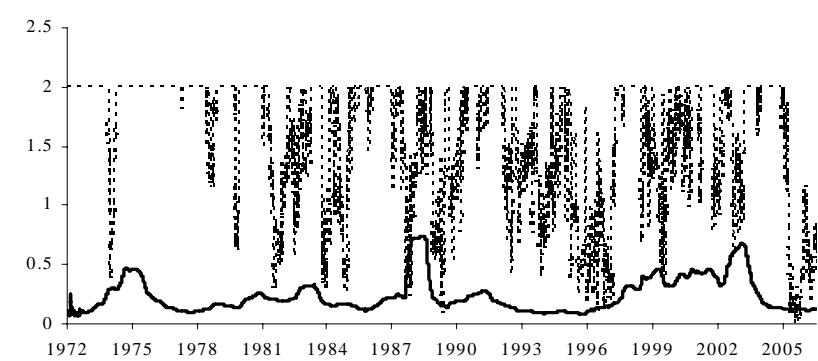

…... CHF $\longrightarrow$ R Sq. Bound

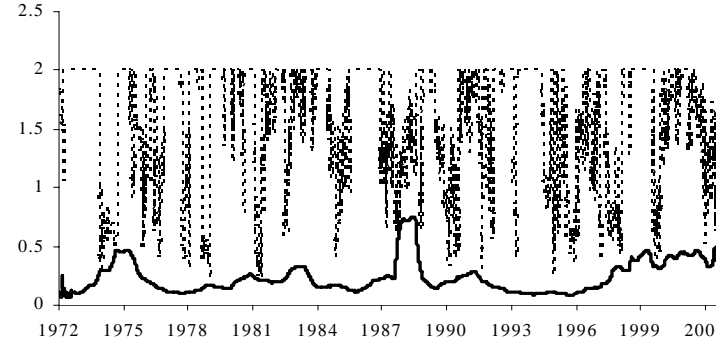

…....JPY — R Sq. Bound

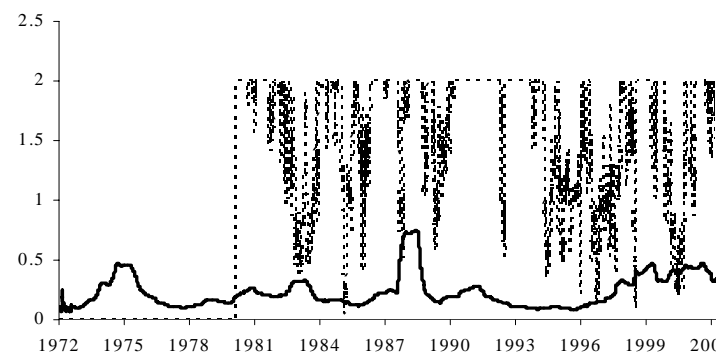

…...ECU/EUR —

Notes. These figures plot the sequences of the percentage coefficients of determinations (shown by the dotted line) of rolling AR(5) auto-regressions for each currency in our sample against their upper bound (shown by the solid line). The latter is computed under a relative risk aversion upper bound of 5 . The estimation window of each auto-regression is one year and the sample period is 1971-2006. The values of all the series have been cut off at 2.0 to improve visual clarity. 
Table 1

Frequency of Boundary Violations

(Daily Data)

\begin{tabular}{llrrrr}
\hline & & $\mathbf{1 9 7 1 - 2 0 0 6}$ & $\mathbf{1 9 7 1 - 1 9 8 3}$ & $\mathbf{1 9 8 4 - 1 9 9 5}$ & $\mathbf{1 9 9 6 - 2 0 0 6}$ \\
\hline AUD & $(1)$ & 9001 & 3056 & 3130 & 2815 \\
& $(2)$ & 8686 & 2809 & 3067 & 2810 \\
& $(3)$ & 96.5 & 91.9 & 98.0 & 99.8 \\
CAD & $(1)$ & 9001 & 3056 & 3130 & 2815 \\
& $(2)$ & 8923 & 3056 & 3081 & 2786 \\
& $(3)$ & 99.1 & 100.0 & 98.4 & 99.0 \\
JPY & $(1)$ & 9001 & 3056 & 3130 & 2815 \\
& $(2)$ & 8995 & 3053 & 3129 & 2813 \\
& $(3)$ & 99.9 & 99.9 & 100.0 & 99.9 \\
GBP & $(1)$ & 9001 & 3056 & 3130 & 2815 \\
& $(2)$ & 8890 & 3045 & 3102 & 2743 \\
& $(3)$ & 98.8 & 99.6 & 99.1 & 97.4 \\
CHF & $(1)$ & 9001 & 3056 & 3130 & 2815 \\
& $(2)$ & 8902 & 3056 & 3111 & 2735 \\
& $(3)$ & 98.9 & 100.0 & 99.4 & 97.2 \\
ECU/EUR & $(1)$ & 6751 & 806 & 3130 & 2815 \\
& $(2)$ & 6675 & 805 & 3118 & 2752 \\
& $(3)$ & 98.9 & 99.9 & 99.6 & 97.8 \\
\hline
\end{tabular}

Notes. This table reports (1) the number of rolling yearly $\mathrm{R}^{2}$ estimates for each currency over the full sample period and in each sub-sample period, (2) the number and the (3) percentage frequency of positive BVI values, i.e. (2) over (1). The BVI is calculated as explained in the text, under a RRA upper-bound equal to 5 . The predictive regressions are estimated over rolling 1-year windows of daily data, throughout the sub-sample periods specified in the first column. 
Table 2

Excess-Predictability in Annualized SR Units

\begin{tabular}{|c|c|c|c|c|c|c|c|}
\hline & AUD & CAD & JPY & GBP & CHF & $\begin{array}{l}\text { ECU/ } \\
\text { EUR }\end{array}$ & Avg. \\
\hline \multicolumn{8}{|c|}{ Daily } \\
\hline \multicolumn{8}{|c|}{$\operatorname{ARMA}(5,0)$} \\
\hline 1971-1976 & - & 174.9 & 135.9 & 180.0 & 116.1 & & 137.8 \\
\hline 1977-1982 & 158.7 & 126.8 & 44.4 & 80.6 & 43.8 & & 92.8 \\
\hline 1983-1988 & 62.8 & 90.7 & 125.4 & 126.4 & 18.2 & - & 85.8 \\
\hline 1989-1994 & 100.5 & 60.1 & 38.0 & 72.0 & 31.5 & 121.1 & 77.5 \\
\hline 1995-2000 & 60.5 & 82.0 & - & 128.3 & - & - & 66.9 \\
\hline 2001-2006 & 78.2 & 113.8 & 19.6 & - & 122.1 & 97.7 & 85.5 \\
\hline \multicolumn{8}{|c|}{ Monthly } \\
\hline \multicolumn{8}{|c|}{$\operatorname{ARMA}(5,2)$} \\
\hline 1971-1976 & 134.1 & 76.2 & 152.9 & 97.9 & 198.0 & & 121.5 \\
\hline 1977-1982 & 25.5 & 146.2 & 211.3 & 104.5 & 63.1 & & 112.4 \\
\hline 1983-1988 & 158.0 & 25.7 & 80.1 & & 92.8 & 60.7 & 85.3 \\
\hline 1989-1994 & 62.4 & 87.2 & 10.4 & 136.6 & 111.3 & 116.1 & 96.7 \\
\hline 1995-2000 & 107.1 & 58.7 & 92.1 & 123.1 & 125.2 & 71.3 & 99.4 \\
\hline 2001-2006 & 77.1 & 65.2 & 125.6 & 25.5 & 30.4 & 238.0 & 118.5 \\
\hline
\end{tabular}

Notes. This table reports $\gamma_{i}$, i.e. the percentage square root of the annualized average BVI for each currency and its average across currencies. The BVI is calculated under a RRA upper bound equal to 5 . 


\section{Figure 2 \\ Daily Excess-Predictability}

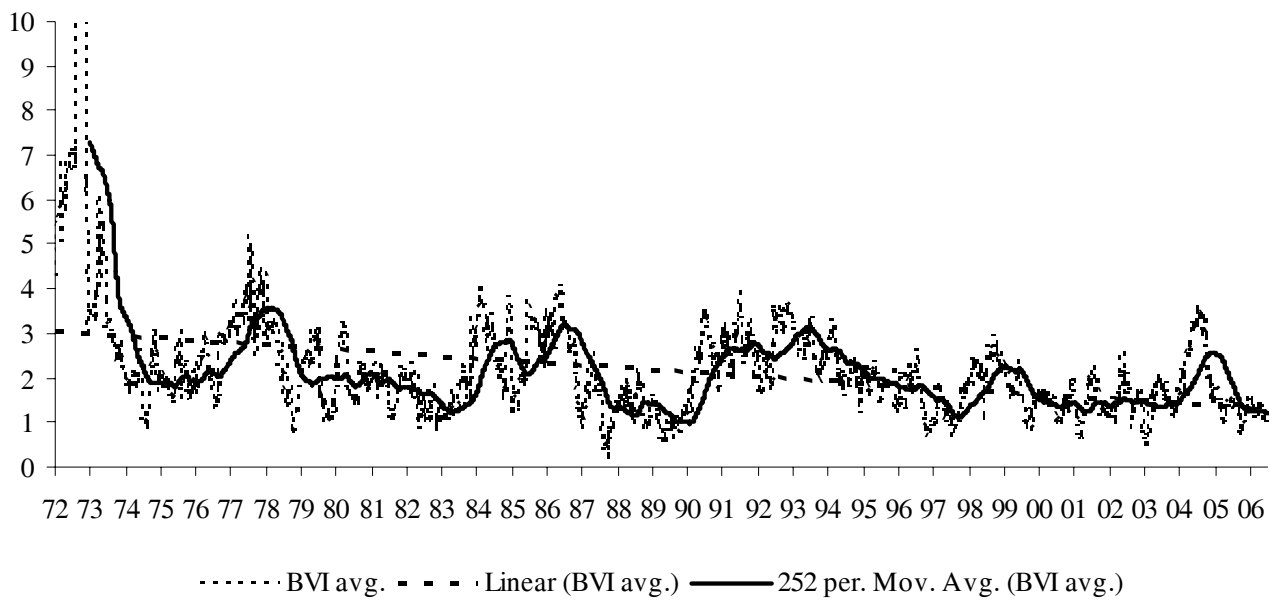

Notes. This figure plots, for each point in our sample period, the average of the percentage BVI over the cross-section of the currencies in our sample. The latter is based, for all currencies, on rolling AR(5) auto-regressions and a RRA upper bound of 5, i.e. $\mathrm{RRA}_{\mathrm{V}}=5$. The estimation window of each auto-regression is one year and the sample period is 1971-2006. The average BVI series has been cut off at 10.0 for improved visual clarity. The solid and dotted lines in bold are a 252-day moving average and a linear interpolation, respectively, of the average BVI series. 
Figure 3

Weights for the Maximal SR Strategy for the Canadian Dollar

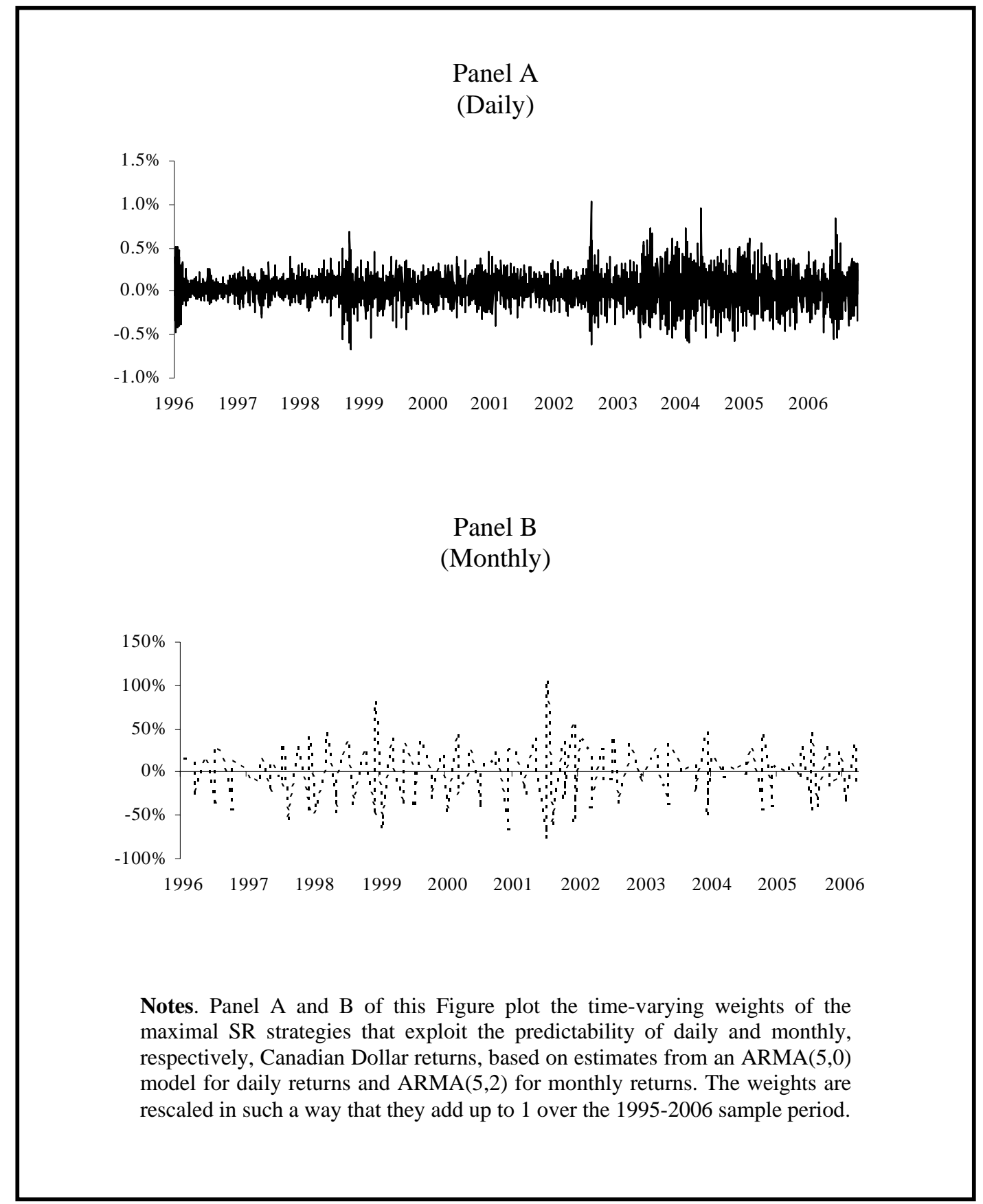


Table 3

Impact of Transaction Costs on Percentage SRs of Predictability-Based Strategies

\begin{tabular}{|c|c|c|c|c|c|c|c|}
\hline $\begin{array}{l}\text { Transaction } \\
\text { costs (bps) }\end{array}$ & $\mathbf{0}$ & 2 & 3 & 5 & 25 & $\begin{array}{l}\text { Bound } \\
\text { RRA }_{V} \\
=2.5\end{array}$ & $\begin{array}{l}\text { Bound } \\
\text { RRA }_{V} \\
=5.0 \\
\end{array}$ \\
\hline \multicolumn{8}{|c|}{ Daily } \\
\hline \multicolumn{6}{|c|}{ (1995-2006) } & \multirow[t]{7}{*}{46.0} & \multirow[t]{7}{*}{88.0} \\
\hline AUD & *57.3 & 17.4 & -2.3 & -41.7 & & & \\
\hline CAD & $* * 130.1$ & $* 47.1$ & 5.62 & -77.4 & & & \\
\hline JPY & *49.1 & -11.0 & -41.1 & -101.2 & & & \\
\hline GBP & $* 48.4$ & 20.0 & 5.7 & -22.7 & & & \\
\hline $\mathrm{CHF}$ & **104.3 & $* 47.7$ & 19.6 & -36.7 & & & \\
\hline \multirow[t]{2}{*}{ ECU/EUR } & *82.1 & 22.7 & -7.1 & -66.6 & & & \\
\hline & \multicolumn{3}{|c|}{$\begin{array}{c}\text { Monthly } \\
(1972-2006)\end{array}$} & & & \multirow{6}{*}{39.2} & \multirow{6}{*}{78.3} \\
\hline AUD & *43.3 & $* 40.9$ & *39.8 & 37.4 & 14.0 & & \\
\hline CAD & *39.5 & 34.0 & 31.1 & 25.6 & -30.7 & & \\
\hline JPY & *53.0 & *51.4 & *50.6 & $* 48.9$ & 32.2 & & \\
\hline GBP & 37.4 & 35.5 & 3.5 & 32.5 & 12.7 & & \\
\hline $\mathrm{CHF}$ & *60.2 & $* 58.0$ & $* 57.0$ & $* 54.8$ & 32.7 & & \\
\hline \multirow{2}{*}{\multicolumn{6}{|c|}{ ECU/EUR }} & \multirow{7}{*}{40.1} & \multirow{7}{*}{80.1} \\
\hline & & & & & & & \\
\hline AUD & *52.3 & *50.6 & *49.6 & $* 47.7$ & 27.3 & & \\
\hline CAD & $* * 130.9$ & $* * 123.8$ & $* * 120.3$ & $* * 113.0$ & 35.7 & & \\
\hline JPY & $* * 128.0$ & $* * 126.4$ & $* * 125.7$ & $* * 124.2$ & **109.2 & & \\
\hline GBP & $* * 181.4$ & $* * 179.2$ & $* * 178.1$ & $* * 175.9$ & $* * 154.0$ & & \\
\hline $\mathrm{CHF}$ & *76.01 & *74.3 & *73.4 & *71.7 & *54.1 & & \\
\hline \multirow{2}{*}{\multicolumn{6}{|c|}{ ECU/EUR }} & \multirow{7}{*}{44.0} & \multirow{8}{*}{87.8} \\
\hline \multicolumn{3}{|c|}{ (1983-1994) } & & & & & \\
\hline AUD & *75.5 & *73.7 & *72.8 & $* 71.0$ & $* 52.8$ & & \\
\hline CAD & $* 74.4$ & *69.8 & *67.5 & *62.9 & 16.2 & & \\
\hline JPY & $* * 93.4$ & $* * 91.3$ & **90.3 & $* * 88.2$ & *66.8 & & \\
\hline GBP & *54.6 & *52.9 & $* 52.1$ & *51.3 & 33.6 & & \\
\hline $\mathrm{CHF}$ & $* 63.0$ & $* 60.8$ & $* 59.7$ & $* 57.5$ & 34.8 & & \\
\hline ECU/EUR & $* 85.8$ & *83.0 & *81.5 & $* 78.7$ & 49.4 & \multirow{8}{*}{38.6} & \\
\hline \multicolumn{6}{|c|}{$(1995-2006)$} & & \multirow[t]{7}{*}{77.1} \\
\hline AUD & $* 81.5$ & *79.2 & *78.0 & $* 75.7$ & *51.9 & & \\
\hline CAD & *72.0 & *68.1 & *66.1 & *62.0 & 20.3 & & \\
\hline JPY & $* * 106.4$ & $* * 105.0$ & $* * 104.4$ & $* * 103.0$ & $* * 89.6$ & & \\
\hline GBP & **78.6 & $* 75.0$ & *73.3 & 69.8 & 34.1 & & \\
\hline $\mathrm{CHF}$ & *56.0 & $* 54.9$ & $* 54.4$ & *53.4 & $* 43.7$ & & \\
\hline ECU/EUR & $* 63.9$ & $* 62.2$ & $* 61.3$ & $* 59.7$ & $* 42.8$ & & \\
\hline
\end{tabular}

Notes. This Table reports percentage annualized Sharpe ratios of strategies that optimally exploit estimated predictability of daily and monthly currency returns, as a function of various levels of transaction costs (in basis points in the top row). The estimated daily predictive regression models are $\operatorname{ARMA}(5,0)$ for all currencies. The estimated monthly predictive regression models are $\operatorname{ARMA}(5,2)$ for all currencies. The last two columns report the annualized maximal SR bounds under RRA upper bounds equal to 2.5 and 5 . The SR bound is computed by taking the square root of the predictability bound and annualizing. One and two asterisks are used to draw attention to SRs in excess of the bound corresponding to RRA $=2.5$ and RRA $=5$, respectively. 
Figure 4

Monthly Excess-Predictability Adjusted for Hosking's (1979) Sampling Error

(Rolling 5-Year Estimation Windows)
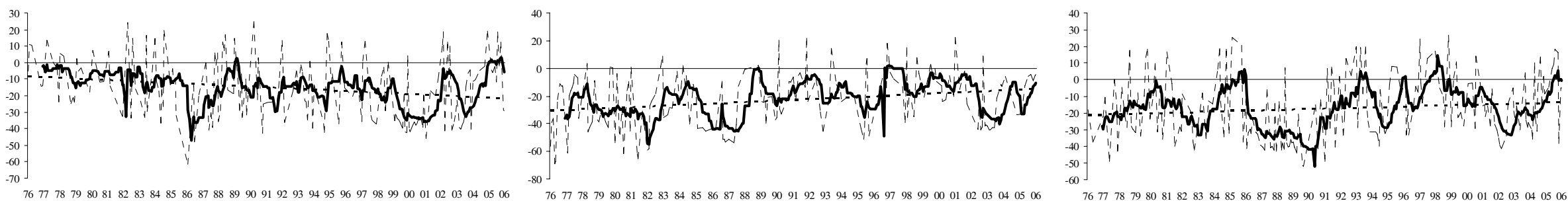

- - - AUD — 12 per. Mov. Avg. (AUD) - - - . Linear (AUD)

- - - CAD 12 per. Mov. Avg. (CAD) - . . . L Linear (CAD)
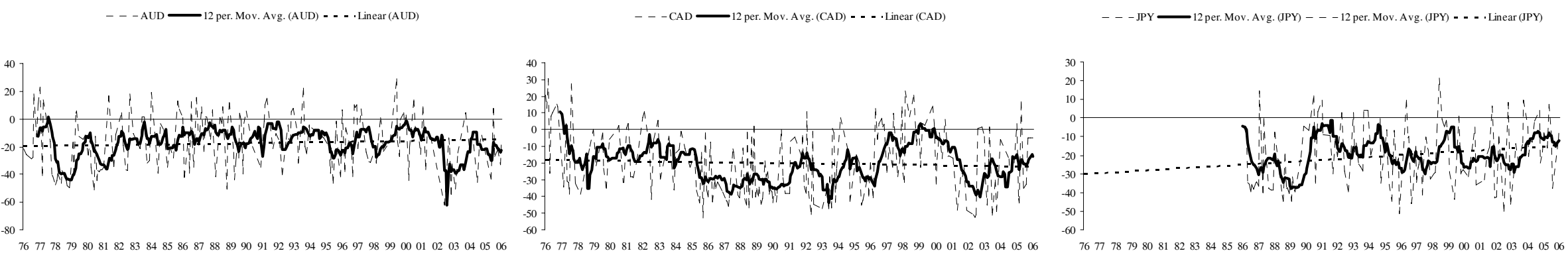

- - - $\mathrm{CHF} \longrightarrow 12$ per. Mov.Avg. (CHF) - . . . . Linear (CHF)

- _ - ECU/EUR — 12 per Mov Avg (ECU/EUR) . . . . .Linear (FCU/EURP)

Notes. These figures plot, for each point in our sample period and each currency in our sample, the percentage BVI adjusted for Hosking's (1979) sampling error, i.e. $B V I_{i, a d j}$. based on rolling ARMA(5,2) predictive regressions and a RRA upper bound of 5, i.e. $\mathrm{RRA}_{\mathrm{V}}=5$. The estimation window of each autoregression is 5 years of monthly data from 1971 to 2006. The solid and dotted lines in bold are a 12-month moving average and a linear interpolation, respectively, of the BVI series. The estimation is conducted using the Broyden, Fletcher, Goldfarb and Shanno method described in Press et al. (1988). 
Table 4

Monthly Excess Predictability Adjusted for Hosking's (1979) Sampling Error (Non Overlapping 5-Year Estimation Windows)

\begin{tabular}{|c|c|c|c|c|c|c|c|c|c|}
\hline & & AUD & CAD & JPY & GBP & CHF & $\begin{array}{l}\text { ECU/ } \\
\text { EUR }\end{array}$ & $\begin{array}{l}\text { Bound } \\
\text { RRA }_{V} \\
=2.5\end{array}$ & $\begin{array}{l}\text { Bound } \\
\text { RRA }_{V} \\
=5.0\end{array}$ \\
\hline \multirow[t]{7}{*}{ 1971-1976 } & $\mathrm{R}^{2}$ & 21.18 & 11.03 & 25.67 & 14.17 & 38.86 & & 1.55 & 6.19 \\
\hline & $\mathrm{H}\left(\mathrm{R}_{\mathrm{RRA}=2.5}^{2}\right)$ & $* * 3.26$ & 1.15 & $* * 2.82$ & *1.43 & $* * 4.49$ & & & \\
\hline & p-value & $(0.001)$ & $(0.266)$ & $(0.002)$ & $(0.077)$ & $(0.000)$ & & & \\
\hline & $\gamma_{a d j, \mathrm{RRA}=2.5}$ & 108.21 & - & 110.19 & - & 168.98 & & & \\
\hline & $\mathrm{H}\left(\mathrm{R}_{\mathrm{RRA}=5.0}^{2}\right)$ & $* * 2.55$ & 0.33 & $* * 2.34$ & 0.99 & $* * 4.08$ & & & \\
\hline & p-value & $(0.005)$ & $(0.372)$ & $(0.010)$ & $(0.162)$ & $(0.000)$ & & & \\
\hline & $\gamma_{a d j, \mathrm{RRA}=5.0}$ & 80.16 & - & 83.52 & - & 154.76 & & & \\
\hline \multirow[t]{7}{*}{ 1977-1982 } & $\mathrm{R}^{2}$ & 5.30 & 22.56 & 41.96 & 13.86 & 8.08 & & 1.19 & 4.76 \\
\hline & $\mathrm{H}\left(\mathrm{R}_{\mathrm{RRA}=2.5}^{2}\right)$ & 0.56 & $* 1.47$ & $* * 4.31$ & 1.14 & 0.78 & & & \\
\hline & p-value & $(0.287)$ & $(0.071)$ & $(0.000)$ & $(0.128)$ & $(0.219)$ & & & \\
\hline & $\gamma_{a d j, \mathrm{RRA}=2.5}$ & - & - & 174.10 & - & - & & & \\
\hline & $\mathrm{H}\left(\mathrm{R}_{\mathrm{RRA}=5.0}^{2}\right)$ & 0.08 & 1.24 & $* * 4.01$ & 0.83 & 0.38 & & & \\
\hline & p-value & $(0.470)$ & (0.107) & $(0.000)$ & $(0.203)$ & $(0.351)$ & & & \\
\hline & $\gamma_{a d j, \mathrm{RRA}=5.0}$ & - & - & 162.39 & - & - & & & \\
\hline \multirow[t]{7}{*}{ 1983-1988 } & $\mathrm{R}^{2}$ & 27.17 & 6.91 & 11.71 & 5.82 & 13.54 & 9.43 & 1.59 & 6.36 \\
\hline & $\mathrm{H}\left(\mathrm{R}_{\mathrm{RRA}=2.5}^{2}\right)$ & $* * 2.45$ & 0.49 & 0.85 & 0.40 & 0.90 & 0.70 & & \\
\hline & p-value & $(0.007)$ & (0.313) & (0.198) & $(0.345)$ & $(0.184)$ & $(0.241)$ & & \\
\hline & $\gamma_{a d j, \mathrm{RRA}=2.5}$ & 100.57 & - & - & - & - & - & & \\
\hline & $\mathrm{H}\left(\mathrm{R}_{\mathrm{RRA}=5.0}^{2}\right)$ & $* * 2.04$ & 0.05 & 0.46 & -0.05 & 0.55 & 0.28 & & \\
\hline & p-value & $(0.021)$ & $(0.479)$ & $(0.322)$ & $(0.521)$ & $(0.290)$ & (0.389) & & \\
\hline & $\gamma_{a d j, \mathrm{RRA}=5.0}$ & 69.95 & - & - & - & - & - & & \\
\hline \multirow[t]{7}{*}{ 1989-1994 } & $\mathrm{R}^{2}$ & 6.39 & 9.49 & 3.24 & 18.70 & 13.47 & 14.39 & 0.79 & 3.15 \\
\hline & $\mathrm{H}\left(\mathrm{R}_{\mathrm{RRA}=2.5}^{2}\right)$ & 0.62 & 0.68 & 0.28 & $* * 1.88$ & 1.08 & *1.35 & & \\
\hline & p-value & (0.269) & $(0.247)$ & (0.389) & $(0.030)$ & $(0.140)$ & (0.088) & & \\
\hline & $\gamma_{a d j, \mathrm{RRA}=2.5}$ & - & - & - & 52.00 & - & - & & \\
\hline & $\mathrm{H}\left(\mathrm{R}_{\mathrm{RRA}=5.0}^{2}\right)$ & 0.36 & 0.50 & 0.01 & **1.65 & 0.89 & 1.13 & & \\
\hline & p-value & (0.359) & $(0.307)$ & $(0.496)$ & $(0.050)$ & $(0.187)$ & (0.129) & & \\
\hline & $\gamma_{a d j, \mathrm{RRA}=5.0}$ & - & - & - & 9.67 & - & - & & \\
\hline \multirow[t]{7}{*}{$1995-2000$} & $\mathrm{R}^{2}$ & 14.30 & 7.61 & 11.81 & 17.37 & 17.80 & 8.98 & 1.19 & 4.74 \\
\hline & $\mathrm{H}\left(\mathrm{R}_{\mathrm{RRA}=2.5}^{2}\right)$ & 1.03 & 0.82 & 1.27 & $* 1.51$ & $* * 2.27$ & 1.07 & & \\
\hline & p-value & $(0.152)$ & $(0.205)$ & $(0.103)$ & $(0.066)$ & $(0.012)$ & $(0.142)$ & & \\
\hline & $\gamma_{a d j, \mathrm{RRA}=2.5}$ & - & - & - & - & 74.25 & - & & \\
\hline & $\mathrm{H}\left(\mathrm{R}_{\mathrm{RRA}=5.0}^{2}\right)$ & 0.76 & 0.37 & 0.86 & 1.20 & $* * 1.81$ & 0.59 & & \\
\hline & p-value & $(0.223)$ & $(0.354)$ & $(0.195)$ & $(0.115)$ & $(0.035)$ & $(0.277)$ & & \\
\hline & $\gamma_{a d j, \mathrm{RRA}}=5.0$ & - & - & - & - & 38.81 & - & & \\
\hline \multirow[t]{7}{*}{ 2001-2006 } & $\mathrm{R}^{2}$ & 9.17 & 7.75 & 17.36 & 4.75 & 4.98 & 7.02 & 1.05 & 4.21 \\
\hline & $\mathrm{H}\left(\mathrm{R}_{\mathrm{RRA}=2.5}^{2}\right)$ & 0.83 & 0.72 & 1.60 & 0.37 & 0.38 & 0.56 & & \\
\hline & p-value & $(0.203)$ & $(0.236)$ & $(0.055)$ & $(0.357)$ & $(0.353)$ & (0.289) & & \\
\hline & $\gamma_{a d j, \mathrm{RRA}=2.5}$ & - & - & - & - & - & - & & \\
\hline & $\mathrm{H}\left(\mathrm{R}_{\mathrm{RRA}=5.0}^{2}\right)$ & 0.52 & 0.39 & 1.31 & 0.05 & 0.07 & 0.26 & & \\
\hline & p-value & (0.303) & $(0.350)$ & $(0.095)$ & $(0.479)$ & $(0.470)$ & (0.397) & & \\
\hline & $\gamma_{a d j, \mathrm{RRA}=5.0}$ & - & - & - & - & - & - & & \\
\hline
\end{tabular}

Notes. This table reports, for six sample periods of about equal length, the percentage coefficient of determination of $\operatorname{ARMA}(5,2)$ predictive regressions estimated using monthly data, together with Hosking's (1979) statistic and associated p-value under the null that RRA $=2.5$ and RRA $=5$, and the corresponding percent $\gamma_{a d j}$, computed as the square root of the annualized BVI $-1.64 \times$ s.e. $\left(\mathrm{R}^{2}\right)$. One and two asterisks are used to draw attention to when Hosking's (1979) statistic is significant at the 10 and 5 percent level, respectively. The estimation method is maximum likelihood. 
Table 5

Bootstrapped Percent $\mathbf{R}^{2}$ Distribution

Monthly Predictability

\begin{tabular}{|c|c|c|c|c|}
\hline & 1971-2006 & 1971-1982 & 1983-1994 & 1995-2006 \\
\hline Bound $_{\mathrm{RRA}=2.5}$ & 1.28 & 1.34 & 1.61 & 1.24 \\
\hline \multirow[t]{2}{*}{ Bound $_{\mathrm{RRA}=5}$} & 5.11 & 5.35 & 6.43 & 4.95 \\
\hline & & $\operatorname{ARMA}(5,0)$ & & \\
\hline AUD & 0.514 .17 & *1.51 12.17 & *2.49 15.90 & *1.28 10.18 \\
\hline CAD & $0.47 \quad 3.77$ & *4.81 19.29 & NA & *1.36 11.71 \\
\hline JPY & $0.57 \quad 4.28$ & *1.52 12.89 & 1.0010 .06 & *3.96 18.18 \\
\hline GBP & 0.423 .63 & *2.55 15.03 & 1.2910 .61 & *2.23 14.08 \\
\hline $\mathrm{CHF}$ & 0.524 .22 & 1.0910 .51 & 1.189 .78 & *1.43 12.02 \\
\hline \multirow[t]{2}{*}{ ECU/EUR } & & & 1.049 .17 & *1.37 11.62 \\
\hline & & $\operatorname{ARMA}(5,2)$ & & \\
\hline AUD & *1.38 24.15 & *2.93 17.43 & *5.15 23.39 & *3.55 28.81 \\
\hline CAD & 1.126 .09 & $* * 9.3730 .36$ & *3.34 17.95 & *3.33 15.52 \\
\hline JPY & *2.94 64.38 & **6.89 63.83 & *4.23 27.30 & **8.05 25.03 \\
\hline GBP & 1.247 .21 & *4.8018.05 & *3.14 16.04 & *3.93 18.26 \\
\hline $\mathrm{CHF}$ & *1.76 8.31 & *3.17 17.25 & *3.92 19.55 & *4.25 17.07 \\
\hline ECU/EUR & & & *3.87 20.13 & *3.3614.62 \\
\hline
\end{tabular}

Notes. The first two rows of this table report monthly percentage unconditional upper bounds on the explanatory power of predictive regressions under a relative risk aversion upper bound equal to 2.5 and 5 , respectively. The other rows report, for each currency, the bootstrapped 90 percent two-tailed confidence intervals (in percentage) for the predictive regression coefficient of determination. The bootstrapping experiment is conducted by re-sampling 1,000 times, in blocks of 5 at a time, the residuals of the estimated monthly predictive model. The latter is AR(5), for the top panel, and $\operatorname{ARMA}(5,2)$ for the bottom panel. The sample periods are 1971-2006 and three subsamples of about equal length, 1971-1982, 1983-1994, 1995-2006. In the table, one and two asterisks denote when the upper bound is violated at the significance level corresponding to the value reported in the left-most column under a RRA bound of 2.5 and 5 , respectively. 
Table 6

SRs, Correlations and Factor Structure of Maximal-SR Strategies

\begin{tabular}{|c|c|c|c|c|c|c|c|c|c|}
\hline & $\mathrm{w}^{*}$ & SR & $\begin{array}{l}\text { Corr. } \\
\text { vs. } r^{*}\end{array}$ & $\begin{array}{l}\text { Corr. } \\
\text { vs. } \\
\text { AFX }\end{array}$ & alpha & $\mathbf{R}_{\mathrm{m}}-\mathbf{R}_{\mathrm{f}}$ & SMB & HML & GRS \\
\hline & & & & $\begin{array}{l}\text { anel A } \\
34-2006)\end{array}$ & & & & & \\
\hline AUD & 46.1 & 43.9 & 58.8 & 22.5 & $\begin{array}{l}* 0.45 \\
(2.54)\end{array}$ & $\begin{array}{c}*-5.17 \\
(-2.27)\end{array}$ & $\begin{array}{r}*-11.78 \\
(-2.44)\end{array}$ & $\begin{array}{l}*-8.86 \\
(-2.04)\end{array}$ & \\
\hline CAD & 15.9 & 15.4 & 20.7 & 4.3 & $\begin{array}{r}0.16 \\
(0.57)\end{array}$ & $\begin{array}{r}6.52 \\
(1.09)\end{array}$ & $\begin{array}{r}5.49 \\
(0.49)\end{array}$ & $\begin{array}{r}0.85 \\
(0.10)\end{array}$ & \\
\hline JPY & 31.6 & 43.9 & 58.8 & 19.1 & $\begin{array}{l}* 0.59 \\
(2.22)\end{array}$ & $\begin{array}{r}*-12.44 \\
(-2.09)\end{array}$ & $\begin{array}{r}-5.41 \\
(-0.80)\end{array}$ & $\begin{array}{r}*-15.19 \\
(-2.01)\end{array}$ & \\
\hline GBP & 4.4 & 24.3 & 32.5 & 21.8 & $\begin{array}{r}0.52 \\
(1.30)\end{array}$ & $\begin{array}{r}*-14.55 \\
(-3.06)\end{array}$ & $\begin{array}{r}2.12 \\
(0.19)\end{array}$ & $\begin{array}{l}-10.91 \\
(-1.45)\end{array}$ & \\
\hline CHF & -15.6 & 35.3 & 47.3 & 41.8 & $\begin{array}{l}* 0.19 \\
(2.71)\end{array}$ & $\begin{array}{l}*-3.75 \\
(-2.17)\end{array}$ & $\begin{array}{r}-3.99 \\
(-1.70)\end{array}$ & $\begin{array}{l}*-6.37 \\
(-2.42)\end{array}$ & \\
\hline ECU-EUR & 17.6 & 39.6 & 53.1 & 45.0 & $\begin{array}{l}* 0.85 \\
(2.60)\end{array}$ & $\begin{array}{r}-6.27 \\
(-0.59)\end{array}$ & $\begin{array}{l}-10.27 \\
(-0.73)\end{array}$ & $\begin{array}{l}-17.62 \\
(-1.23)\end{array}$ & \\
\hline & & & & & & & & & $\begin{array}{r}* 2.79 \\
(0.012)\end{array}$ \\
\hline $\mathrm{r}^{*}$ & 100.0 & 74.7 & 100.0 & 46.9 & $\begin{array}{l}* 0.56 \\
(4.11)\end{array}$ & $\begin{array}{l}*-6.44 \\
(-1.97)\end{array}$ & $\begin{array}{r}-7.39 \\
(-1.59)\end{array}$ & $\begin{array}{r}*-11.38 \\
(-2.67)\end{array}$ & \\
\hline AFX & & 56.7 & 46.9 & 100.0 & $\begin{array}{l}* 0.34 \\
(2.72)\end{array}$ & $\begin{array}{r}0.52 \\
(0.17)\end{array}$ & $\begin{array}{l}*_{-4.71} \\
(-1.11)\end{array}$ & $\begin{array}{r}-3.60 \\
(-0.92)\end{array}$ & \\
\hline & & & & $\begin{array}{l}\text { anel B } \\
96-2006)\end{array}$ & & & & & \\
\hline AUD & 6.9 & 44.2 & 31.8 & 10.2 & $\begin{array}{r}0.34 \\
(1.18)\end{array}$ & $\begin{array}{r}7.68 \\
(1.11)\end{array}$ & $\begin{array}{r}-2.22 \\
(-0.18)\end{array}$ & $\begin{array}{r}5.47 \\
(0.77)\end{array}$ & \\
\hline CAD & 12.5 & 42.7 & 30.7 & 11.2 & $\begin{array}{r}0.38 \\
(1.58)\end{array}$ & $\begin{array}{r}-0.54 \\
(-0.12)\end{array}$ & $\begin{array}{r}14.27 \\
(1.70)\end{array}$ & $\begin{array}{l}-12.52 \\
(-1.35)\end{array}$ & \\
\hline JPY & 30.9 & 74.4 & 53.5 & 4.8 & $\begin{array}{r}0.38 \\
(1.59)\end{array}$ & $\begin{array}{r}3.19 \\
(1.58)\end{array}$ & $\begin{array}{r}*_{-}-17.93 \\
(-3.23)\end{array}$ & $\begin{array}{r}2.11 \\
(0.32)\end{array}$ & \\
\hline GBP & 22.9 & 64.6 & 46.4 & -3.0 & $\begin{array}{l}* 0.45 \\
(2.71)\end{array}$ & $\begin{array}{r}3.15 \\
(0.89)\end{array}$ & $\begin{array}{r}10.25 \\
(1.90)\end{array}$ & $\begin{array}{r}1.29 \\
(0.16)\end{array}$ & \\
\hline $\mathrm{CHF}$ & 21.7 & 59.3 & 42.6 & 23.5 & $\begin{array}{l}* 0.30 \\
(2.07)\end{array}$ & $\begin{array}{r}2.38 \\
(0.77)\end{array}$ & $\begin{array}{r}-1.54 \\
(-0.25)\end{array}$ & $\begin{array}{r}1.84 \\
(0.26)\end{array}$ & \\
\hline ECU-EUR & 5.1 & 53.4 & 38.3 & 40.7 & $\begin{array}{l}* 0.86 \\
(2.21)\end{array}$ & $\begin{array}{l}16.61 \\
(1.19)\end{array}$ & $\begin{array}{r}-5.42 \\
(-0.20)\end{array}$ & $\begin{array}{l}-25.72 \\
(-1.55)\end{array}$ & \\
\hline & & & & & & & & & $\begin{array}{r}* 2.73 \\
(0.016)\end{array}$ \\
\hline $\mathrm{r}^{*}$ & 100.0 & 139.2 & 100.0 & 27.9 & $\begin{array}{r}* 0.40 \\
(4.16)\end{array}$ & $\begin{array}{r}3.53 \\
(1.47)\end{array}$ & $\begin{array}{r}-2.19 \\
(-0.52)\end{array}$ & $\begin{array}{r}-1.14 \\
(-0.25)\end{array}$ & \\
\hline AFX & & 35.8 & 27.9 & 100.0 & $\begin{array}{r}0.20 \\
(1.40)\end{array}$ & $\begin{array}{r}1.01 \\
(0.29)\end{array}$ & $\begin{array}{r}9.52 \\
(1.56)\end{array}$ & $\begin{array}{r}*-11.65 \\
(-1.77)\end{array}$ & \\
\hline
\end{tabular}

Notes. The first column of this table reports the percentage weights $\mathrm{w}^{*}$ with which the maximal Sharpe Ratio predictability-based strategies for each currency enter the overall maximal Sharpe Ratio strategy, denoted by $\mathrm{r}^{*}$. The second column reports annualized Sharpe ratios of these strategies and of the AFX currency management index. The other columns reports the estimated intercept and factor loadings and, in brackets, the associated t-static based on Newy and West (1987) autocorrelation and heteroskedasticity adjusted standard errors. An asterisk denotes significance at the 5 percent level. The last column reports the GRS statistic (and its p-value in brackets) for the 6 individual currencies maximal SR strategies. The hypothesized level of transaction costs is two basis points per each way transaction and the predictive model, to simplify our computational task, is $\operatorname{ARMA}(5,0)$ for all currencies. The data frequency of the underlying return series is monthly. 
Table 7

AFX vs. Maximal SR Strategy

\begin{tabular}{llrrr}
\hline Period & \multicolumn{1}{c}{$\begin{array}{l}\text { Corr. AFX } \\
\text { vs. } \mathrm{r}^{*}\end{array}$} & \multicolumn{1}{c}{$\mathrm{SR}_{\mathrm{AFX}}$} & $\mathrm{SR}_{\mathrm{r}^{*}}$ & \multicolumn{1}{c}{$\begin{array}{c}\text { Corr. SR } \\
\text { vs. } \mathrm{SR}_{\mathrm{r}^{*}}\end{array}$} \\
\hline & & & & \\
$1985-1990$ & 52.36 & 97.17 & 115.89 & 52.92 \\
$1991-1996$ & 46.29 & 38.38 & 58.62 & 45.64 \\
$1997-2002$ & 50.20 & 49.53 & 20.00 & 11.62 \\
$2003-2006$ & 41.08 & -5.44 & 106.14 & -44.55 \\
\hline
\end{tabular}

Notes. This Table reports, for four 5-year periods between 1985 and 2006, the percentage coefficient of correlation between the AFX Currency Management index return and the maximal SR strategy return $\mathrm{r}^{*}$, their SR and the correlation between their 12-month moving.

Figure 5

AFX vs. Maximal SR Strategy

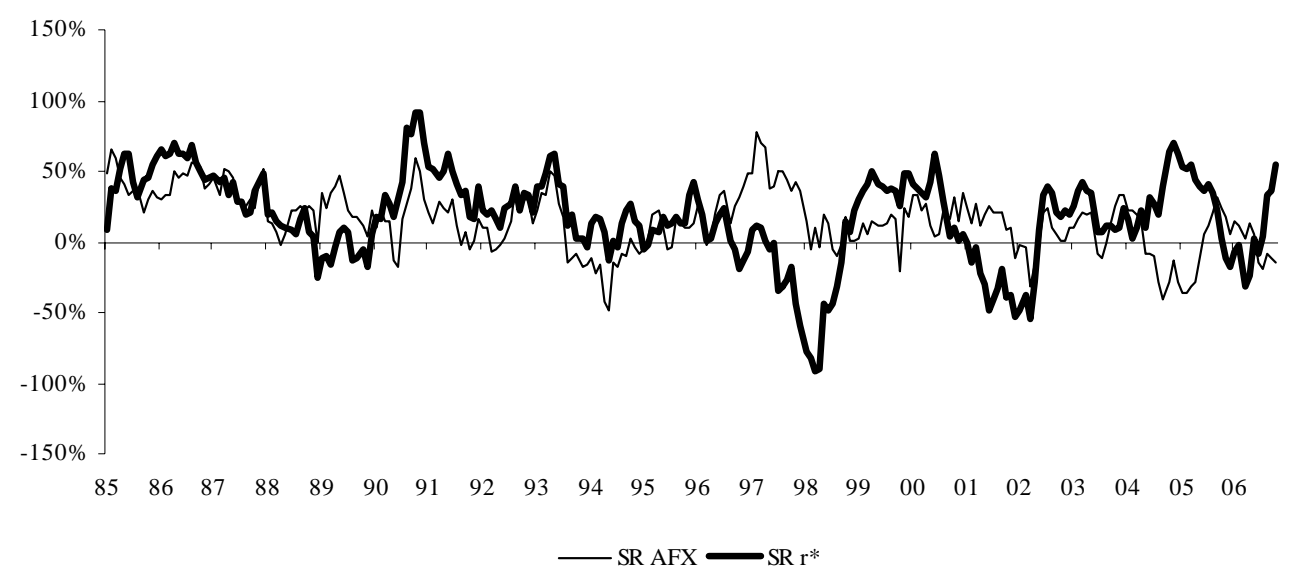

Notes. This Figure plots the rolling 12-month SR of the maximal SR strategy $\mathrm{r}^{*}$ that exploits monthly predictability, based on estimates from an ARMA(5,0) model, and of the AFX Currency Management Index. The sample period is 1984-2006. 


\section{Bibliography}

Andersen, T.G., Bollerslev, T., Diebold, F.X. and H. Ebens, 2001, The Distribution of Stock Return Volatility, Journal of Financial Economics 61, 43-76.

Andersen, T.G., Bollerslev, T., Diebold, F.X. and J. Wu, 2004, Realized Beta: Persistence and Predictability, PIER Working Paper No. 04-018.

Barsky, R.B., F.T. Juster, M.S. Kimball, and M.D. Shapiro, 1997, Preference Parameters and Behavioral Heterogeneity: An Experimental Approach in the Health and Retirement Study, The Quarterly Journal of Economics 112, 537-539.

Berger, D.W., Chaboud, A.P., Chernenko, S.V., Howorka E. and J.H. Write, 2006, Order Flow and Exchange Rate Dynamics in Electronic Brokerage System Data, Board of Governors of the Federal Reserve System.

Box, G.E.P. and G.M. Jenkins (1976), Time Series Analysis, Forecasting and Control, San Francisco: Holden Day.

Burnside, C., M. Eichenbaum, I. Kleschelski, and S. Rebelo. 2006. "The Returns to Currency Speculation,” NBER working paper 12916.

Campbell, J.Y. and S.B. Thompson, 2005, Predicting the Equity Premium Out of Sample: Can Anything Beat the Historical Average? unpublished manuscript.

Cerný, A. and S.D. Hodges, 2000, The Theory of Good-Deal Pricing in Financial Markets, Tanaka Business School Discussion Paper TBS/DP04/14.

Cerný, A. and S.D. Hodges, 2001, The Theory of Good-Deal Pricing in Incomplete Markets, in Mathematical Finance-Bachelier Congress 2000, H. Geman, D. Madan, S. Pliska and T. Vorst, eds. Berlin: Spring, 175-202.

Chang, P. H. K. and C.L. Osler, 1999, Methodical Madness: Technical Analysis and the Irrationality of Exchange-Rate Forecasts, The Economic Journal 109, 636-661.

Cochrane, J.H., 2001, Asset Pricing, Princeton University Press, Princeton.

Cochrane, J.H., 2005, Asset Pricing, $2^{\text {nd }}$ Ed., Princeton University Press, Princeton.

Cochrane, J.H. and J. Saà-Requejo, 2000, Beyond Arbitrage: Good Deal Asset Price Bounds in Incomplete Markets, Journal of Political Economy 108, 79-119.

Deutsche Bank, 2008. “DB Currency Returns: Weekly Update,” October 20.

Dooley, M.P. and J. Shafer. Analysis of Short Run Exchange Rate Behavior: March 1973 - September 1975, 1976, International Finance Discussion Papers, No. 76. Washington, D.C., Federal Reserve System. 
Dooley, M.P. and J. Shafer, 1984, Analysis of Short-Run Exchange Rate Behaviour: March 1973-November 1981, in Bigman, D. and T. Taya (eds.), Exchange Rate and Trade Instability, Ballinger, Cambridge, MA.

Evans, M.D.D., and R.K. Lyons, 2002, Order flow and exchange rate dynamics, Journal of Political Economy 110, 170-180.

Fama, E., 1970, Efficient Capital Markets: a Review of Theory and Empirical Work, Journal of Finance 25, 383-417.

Fama E. and K. French, 1993, Common Risk Factors in the Returns on Stocks and Bonds, Journal Financial Economics 33, 3-56.

Freedman, D.A. and S.C. Peters, 1984, Bootstrapping an Econometric Model: Some Empirical Results, Journal of Business and Economic Statistics 2, 150-158.

Friend, I. and M.E. Blume, 1975, The Demand For Risky Assets, American Economic Review 65, 900-922.

Gelfand, A.E. and A.F.M. Smith, 1990, Sampling Based Approaches to Calculating Marginal Densities, JASA 85, 398-409.

Gelman, A., Carlin, J.B., Stern, H.S. and Donald B. Rubin, 1995, Bayesian Data Analysis. London: Chapman and Hall.

Gencay, R., 1999, Linear, Non-linear and Essential Foreign Exchange Rate Prediction with Simple Technical Trading Rules, Journal of International Economics 47, 91-107.

Gibbson, M., Ross, S.A., and J. Shanken, 1989, A Test of The Efficiency of A Given Portfolio, Econometrica 57, 1121-1152.

Hansen, L.P. and R. Jagannathan, 1991, Implications of Security Market Data for Models of Dynamic Economies, Journal of Political Economy 99, 225-262.

Hosking, J.R.M., 1979, The Asymptotic Distribution of $\mathrm{R}^{2}$ for AutoregressiveMoving Average Time Series Models When Parameters Are Estimated, Biometrika 66, 156-7.

Karolyi, G.A. and B.-C. Kho, 2004, Momentum Strategies: Some Bootstrap Tests, Journal of Empirical Finance 11, 509-536.

Kurz-Kim, Jeong-Ryeol and M. Loretan, 2007, A Note on the Coefficient of Determination in Regression Models with Infinite-Variance Variables, Deutsche Bundesbank Discussion Paper, Series 1: Economic Studies, No 10/2007.

LeBaron, B., 1999, Technical Trading Rule Profitability and Foreign Exchange Intervention, Journal of International Economics 49, 125-143. 
Lequeux, P. and E. Acar, 1998, A Dynamic Index for Managed Currencies Funds Using CME Currency Contracts, European Journal of Finance 4, 311-330.

Levich, R. M. and L.R. Thomas III, 1993, The Significance of Technical TradingRule Profits in the Foreign Exchange Market: A Bootstrap Approach, Journal of International Money and Finance 12, 451-74.

Ljung, G.M. and G.E.P. Box (1978), On a Measure of Lack of Fit in Time Series Models, Biometrika 67, 297-303.

Lo, A.W., 2004, The Adaptive Market Hypothesis: Market Efficiency from an Evolutionary Perspective, Journal of Portfolio Management, $30^{\text {th }}$ Anniversary Issue, 15-29.

Lo, A.W., 2005, Reconciling Efficient Markets with Behavioral Finance: The Adaptive Markets Hypothesis, Journal of Investment Consulting 7, 21-44.

Mehra, R. and E. Prescott, 1985, The Equity Premium Puzzle, Journal of Monetary Economics 15, 145-161.

Meyer, D.J. and J. Meyer, 2005, Relative Risk Aversion: What Do We Know? Journal of Risk and Uncertainty 31, 243-262.

Neely, C., Weller, P., and R. Dittmar, 1997, Is Technical Analysis in the Foreign Exchange Market Profitable? A Genetic Programming Approach, Journal of Financial \& Quantitative Analysis 32, 405-426.

Neely, C.J., Weller, P.A. and J. Ulrich, 2007, The Adaptive Markets Hypothesis: Evidence from the Foreign Exchange Market, FRB of St. Louis Working Paper No. 2006-046B and forthcoming in the Journal of Financial \& Quantitative Analysis. Available at SSRN: $\underline{\text { http://ssrn.com/abstract }=922345}$

Nelson, C.R., 1972, The Interpretation of R2 in Autoregressive-Moving Average Time Series Models, The American Statistician 30, 175-180.

Newy, W.K. and D.K. West, 1987, A Simple, Positive Semi-Definite, Heteroskedasticity and Autocorrelation Consistent Covariance Matrix, Econometrica 55, 703-8.

Okunev, J. and D. White, 2003, Do Momentum-based Strategies Still Work in Foreign Currency Markets? Journal of Financial and Quantitative Analysis 38, 425447.

Olson, D., 2004, Have Trading Rule Profits in the Foreign Exchange Markets declined through time? Journal of Banking and Finance 28, 85-105. 
Pesaran, M.H. and A. Timmermann, Predictability of Stock Returns: Robustness and Economic Significance, Journal of Finance 50, 1201-1228.

Peters, S.C. and D.A. Freedman, 1984, Some Notes on the Bootstrap in Regression Problems, Journal of Business \& Economic Statistics 2, 406-409.

Pojarliev, M. and R.M. Levich. 2008. "Do Professional Currency Managers Beat the Benchmark?” Financial Analysts Journal, Sept/Oct.: 18-32.

Press, W.H., Flannery, B.P., Teukolsky, S.A. and W.T. Vettering, 1988, Numerical Recipes in C, Cambridge University Press, New York.

Pukthuanthong, K., Levich, R. M. and L.R. Thomas III, 2007, Do Foreign Exchange Markets Still Trend? Journal of Portfolio Management, vol. 34, no. 1 (Fall): 114-28..

Roll, R., 1984, A Simple Implicit Measure of the Effective Bid-Ask Spread in Financial Markets, Journal of Finance 39, 1127-1139.

Ross, S.A., 1976, Arbitrage Theory of Capital Asset Pricing, Journal of Economic Theory 13, 341-60.

Ross, S. A., 2005, Neoclassical Finance, Princeton University Press, Princeton, New Jersey.

Schulmeister, S., 2006, The Interaction Between Technical Currency Trading and Exchange Rate Fluctuations, Finance Research Letters 3, 212-233.

Stremme, A., Basu, D. and A. Abhyankar, 2005, The Optimal Use of Return Predictability: An Empirical Analysis, AFA 2006 Boston Meetings, paper available at SSRN: http://ssrn.com/abstract=687083.

Swamy, P.A.V.B, 1970, Efficient Inference in a Random Coefficient Regression Model, Econometrica 38, 311-323.

Sweeney, R. J., 1986, Beating the Foreign Exchange Market, Journal of Finance 41, 163-182.

Taylor, S.J., 1994, Trading Futures Using a Channel Rule: A Study of the Predictive Power of Technical Analysis with Currency Examples, Journal of Futures Markets $14,215-235$.

Taylor, S.J., 2005, Asset Price Dynamics, Volatility and Prediction, Princeton University Press, Princeton, NJ.

White, H., 2000, A Reality Check for Data Snooping, Econometrica 68, 1097-1126. 